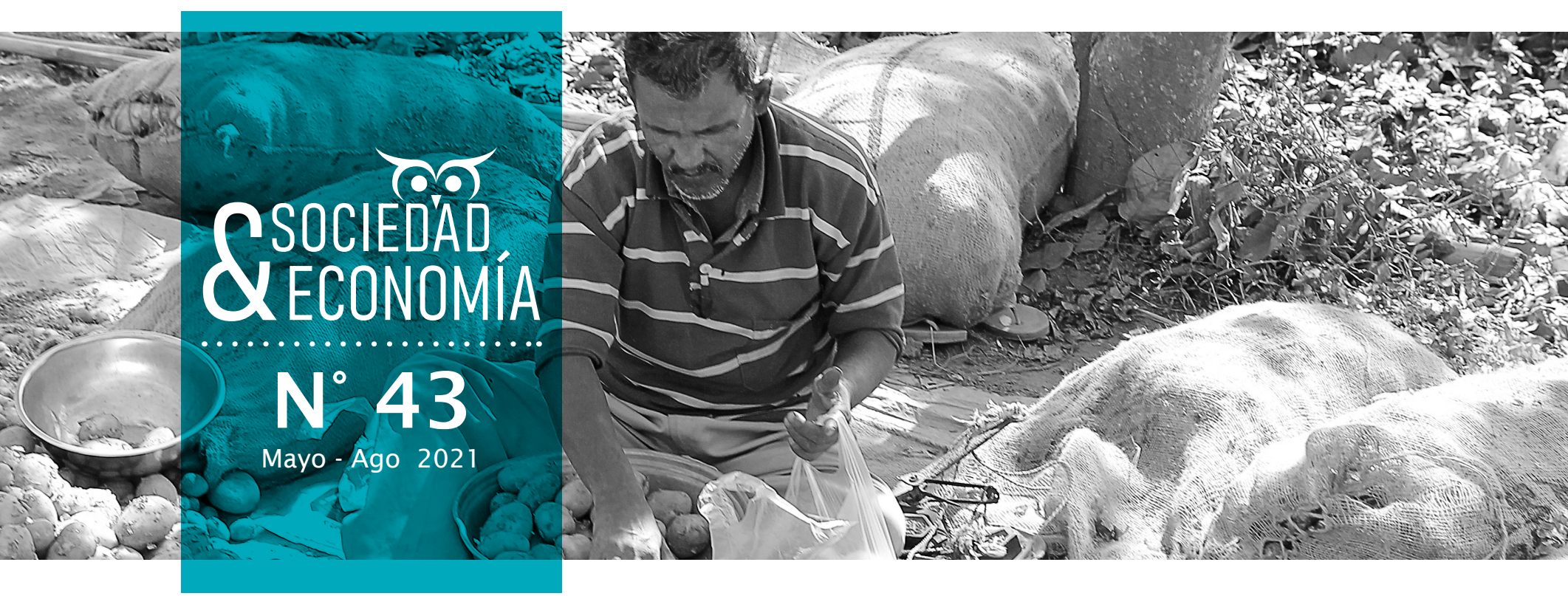

\title{
¿Qué tan lejos está el ODS \# 8 para Colombia? Una década de medición del trabajo decente
}

\author{
How Far is SDG \# 8 for Colombia? A Decade of \\ Measuring Decent Work
}

Silvio Fernando López-Mera'

Universidad de Antioquia, Medellín, Colombia; Universidad Eafit, Medellín, Colombia.

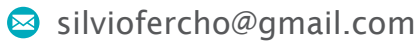

(D) https://orcid.org/0000-0002-7577-0881

Recibido: 21-07-2020

Aceptado: 03-10-2020

Publicado: 01-05-2021

1 Magíster en Economía y en Políticas Públicas. 


\section{Resumen}

En la ruta hacia el cumplimiento de los Objetivos de Desarrollo Sostenibles -ODS- toma relevancia la preocupación por el trabajo decente en las naciones. El estudio, a partir de la Gran Encuesta Integrada de Hogares del DANE, la base de datos RLDatos de riesgos laborales de Fasecolda y el sistema Sislab de la Escuela Nacional Sindical, estima para el periodo 2010-2019 una serie de indicadores que dan cuenta de la realidad, evolución y retos que tiene Colombia en cuanto al cumplimiento del ODS \# 8. Los resultados indican que, antes de iniciar la pandemia, el país ya venía perdiendo parte del terreno recorrido en materia de cantidad y calidad del empleo y que, en materia de trabajo decente, existen diferencias importantes entre territorios y brechas de género, y que, sumadas a la tendencia negativa en varios indicadores, señalan un distanciamiento significativo de las metas del ODS \# 8.

Palabras clave: trabajo decente; ODS; empleo; Colombia; informalidad.

Clasificación JEL: J01, J08, J30, J60.

\section{Abstract}

On the road to the attainment of the Sustainable Development Goals -SDGs- the concern for decent work in nations becomes relevant. This study, based on the DANE's Large Integrated Household Survey, Fasecolda's RLDatos of occupational risks, and the Sislab system of the National Union School, estimates for the period 2010-2019 a set of indicators that account for the reality, evolution, and challenges that Colombia has in the achievement of SDG \# 8. The results indicate that before the start of the pandemic, Colombia had already been losing part of the ground it had accomplished in terms of quantity and quality of employment and that, in terms of decent work, there were important differences between territories and gender gaps, which added to the negative trend in several indicators, indicate a significant distance from the goals of SDG \# 8 .

Keywords: Decent work; SDG; employment; Colombia; informality.

JEL Classification: J01, J08, J30, J60.

\section{Finaciación}

Estudio inspirado en artículos previos sobre economía laboral del autor y por la pertenencia al comité técnico del Observatorio Regional de Mercado de Trabajo (ORMET) de Antioquia. Estudio no financiado.

\section{Conflicto de interés}

El autor declara no tener ningún conflicto de interés en la publicación de este artículo.

Este trabajo está bajo la licencia Atribución-No-Comercial 4.0 Internacional del trabajo decente. Sociedad y economía, (43), e10710914. https://doi.org/10.25100/sye. v0i43.10914 


\section{Introducción}

Con la $87^{\mathrm{a}}$ Conferencia Internacional del Trabajo de Ginebra, realizada por la Organización Internacional del Trabajo (OIT) en 1999, aparece un nuevo concepto en el empleo: el de trabajo decente, como resultado de la precarización del empleo en todo el mundo, las transformaciones sociales y económicas y los nuevos desafíos de una economía mundial. De igual manera, es una respuesta a la necesidad de dignificar al ser humano en el mundo laboral y de reformular objetivos y políticas laborales en los países, especialmente en los menos desarrollados. A partir de esta definición, lo que vino luego fue aterrizar el concepto y buscar mecanismos para su medición. En este proceso, surgen los cuatro pilares del trabajo decente y once dimensiones que contienen, a su vez, un conjunto de indicadores estadísticos y jurídicos para su medición. Diecisiete años después, en el 2015, se gestan los 17 Objetivos de Desarrollo Sostenible (ODS), con el fin de trabajar mundialmente por la erradicación de la pobreza, protección del planeta y la prosperidad de todos los pueblos.

Precisamente en el ODS \# 8, se incluye la concepción de trabajo decente, fruto de considerar que, para crear condiciones suficientes que mitiguen la pobreza y promuevan el desarroIlo humano, se requieren necesariamente empleos decentes (PNUD, 2016). Este es el tema central del presente estudio, el cual tiene como objetivo determinar qué tan distante está Colombia en materia de cumplimiento de los ODS en su componente de trabajo decente antes de que iniciara la pandemia por COVID-19. Para ello, a partir de los microdatos de la Gran Encuesta Integrada de Hogares del DANE (2020), la base de RLDatos de riesgos laborales de Fasecolda (2020) y el sistema Sislab de la Escuela Nacional Sindical (ENS, 2020), el estudio calcula para la década 2010-2019 una serie de indicadores en el marco de las dimensiones del trabajo decente, con los que se identifican los principales avances y retos de Colombia en el cumplimiento de las metas del ODS \# 8. La estimación de los indicadores se realiza para el total de las trece ciudades principales y sus áreas metropolitanas, el agregado nacional y la zona urbana y rural, haciendo una desagre- gación según enfoque de género. Vale mencionar que son pocos los indicadores definidos por el Programa de las Naciones Unidas para el Desarrollo (PNUD), para monitorear el cumplimiento del ODS \# 8 en Colombia y que, en este estudio, se presentan más indicadores para dar mayor información sobre la situación en el país en cada una de las dimensiones que abarca el trabajo decente.

Para ello, el documento se divide en cinco secciones aparte de esta introducción. En la primera sección, se detallan los antecedentes, definición y evolución del concepto de trabajo decente. En la siguiente, se exploran los ODS y en particular el \# 8, así como las metas trazadas por Colombia en materia de trabajo decente. La tercera sección describe los datos y metodología empleada. La siguiente expone, para cada dimensión considerada, los indicadores para su aproximación cuantitativa, así como su respectivo análisis, cumplimiento de Ios ODS y algunas recomendaciones de política pública. La última sección concluye.

\section{Trabajo decente: origen, concepto y evolución}

Es a partir de 1999 cuando se empieza a hablar de trabajo decente en la literatura y en los espacios políticos. Desde ahí se planteó que el trabajo es decente cuando satisface las aspiraciones de la población en el mundo laboral, por tanto, es fuente de dignificación del ser humano y garantía de estabilidad familiar y comunitaria. En términos de la OIT (1999), es el "trabajo productivo en condiciones de libertad, equidad, seguridad y dignidad, en el cual los derechos son protegidos y que cuenta con remuneración adecuada y protección social" ( $p$. 4). Algunos autores manejan los términos de trabajo digno y empleo de calidad como sinónimos de trabajo decente. Al respecto, ha surgido en la literatura un amplio debate. No obstante, los tres términos se inscriben en el mismo esfuerzo de humanizar el trabajo más allá de la visión productivista (Gálvez et al., 2011).

Pineda y Acosta (2011) entienden el trabajo decente y digno como un concepto más am- 
plio y relacionado con la situación laboral, así que cubre el interés por los desempleados, los niños y jóvenes y el resto de grupos etarios, mientras que la calidad del empleo estaría referenciando solo a las personas que se encuentran trabajando. Teniendo claro esto, el trabajo decente se enmarca en cuatro pilares (OIT, 1999; 2015), infundidos a partir de los objetivos que han buscado lograr los acuerdos entre gobierno, empresarios y trabajadores en el marco de la OIT. Estos son:

i. Promover la garantía de los principales y derechos fundamentales en el trabajo, para que los trabajadores tengan representatividad, libertad sindical y de asociación, reconocimiento de derechos a la negociación colectiva y estén ajenos a la discriminación laboral y al trabajo forzoso e infantil.

ii. Crear empleos e ingresos para alcanzar una vida digna y desarrollo personal y social.

iii. Extender la protección social que les permita a hombres y mujeres disfrutar de condiciones seguras en el trabajo y ser parte de inclusión social.

vi. Promover el diálogo social, principalmente entre gobierno, empresarios y trabajadores que mejore la participación ciudadana y la cohesión social.

De esta manera, el trabajo decente es un concepto integrador, ya que incorpora los objetivos estratégicos de la OIT y es, a su vez, universal: aplica para cualquier oficio, trabajador, tipo de trabajo y territorio (Sen, 2000).

Una vez definido el concepto, se ha venido publicando abundante literatura para precisarlo y concretarlo². Para su comprensión, la OIT ha definido 11 dimensiones que le apuntan a los cuatro pilares estratégicos mencionados, a saber (entre paréntesis, se identifica con cuáles de los cuatro pilares se relaciona cada dimensión):

2 Para más detalles sobre el concepto de trabajo decente puede verse Pineda et al. (2013), Somavía (2014) y López (2020). i. Oportunidades de empleo (i,ii): capacidad del mercado para absorber la oferta laboral. Generación de empleos suficientes y dignos. Emparejamiento entre la oferta y demanda de trabajo.

ii. Ingresos adecuados y trabajo productivo (i, iii): remuneración a los trabajadores suficiente para una vida digna. Cumplimiento de mínimos vitales de los trabajadores.

iii. Tiempo de trabajo decente (i, iii): jornada laboral según legislación nacional.

iv. Conciliación del trabajo, la vida familiar y la vida personal (i, iii): conciencia de la vida personal, familiar y social de un trabajador. Destinación del tiempo del trabajador para otras actividades.

v. Trabajo que debería ser abolido (i, iii): erradicación del trabajo infantil. Erradicación del trabajo forzoso.

vi. Estabilidad y seguridad del trabajo (i, ii, iii): grado de estabilidad de los empleos. Duración de los contratos de trabajo. Condiciones contractuales de los trabajadores.

vii. Igualdad de oportunidades y trato en el empleo (i, ii, ii): trato igual en el mundo laboral hacia los hombres y mujeres. Empleos libres de discriminación de todo tipo. Igualdad de oportunidades.

viii. Entorno de trabajo seguro (i, iii): seguridad para los trabajadores en su empleo, bajo la premisa de que los trabajos decentes son seguros.

ix. Seguridad social (i, iii): trabajadores y familiares cubiertos por un sistema de salud y de pensiones. Protección de los trabajadores en situaciones de enfermedad, vejez, incapacidad, desempleo, maternidad, etc. Protección social para los trabajadores.

x. Diálogo social y representación de empleadores y trabajadores (i, iv): espacios para la negociación, consulta e intercambio de información y opiniones en el marco de un 
diálogo social entre gobierno, gremio de empleadores, trabajadores y sindicatos para la promoción de empleos en condiciones de libertad, igualdad, seguridad y dignidad humana.

xi. Contexto económico y social para el trabajo decente: escenario económico y social del territorio adecuado para la consolidación de una política pública de trabajo decente). Esta dimensión se relacionada con el contexto económico y social para el trabajo decente $y$, aunque no es abordada en este estudio, incluye entre otros indicadores, el PIB y contexto de variables macroeconómicas. Para esta dimensión es útil revisar el capítulo de contexto macroeconómico del Marco Fiscal de Mediano Plazo (Ministerio de Hacienda y Crédito Público, 2019).

\section{Los ODS y el trabajo decente: ODS \# 8}

Los Objetivos de Desarrollo Sostenible (Objetivos Mundiales) se gestaron en la Conferencia de la Organización de las Naciones Unidas (ONU) sobre el desarrollo sostenible, realizada en Río de Janeiro en el 2012; teniendo como antecedentes y legado los Objetivos de Desarrollo del Milenio (ODM), los cuales brindaron lecciones aprendidas y experiencias importantes $y$, especialmente, un margen considerable de trabajo y mejora (PNUD, 2016). La intención se basó en la definición de un conjunto de objetivos interrelacionados que dieran cuenta de los desafíos mundiales en materia ambiental, política y socioeconómica y que fueran buscados no solo por los países en desarrollo, sino por todos.

Es así como en el 2015, los 193 Estados Miembros de la ONU adoptan 17 objetivos ambiciosos y 169 metas para el desarrollo sostenible de las economías para el 2030, buscando de esta forma frenar la pobreza, proteger el planeta del cambio climático y promover la paz y la prosperidad en el mundo. Así se da inicio a la Agenda 2030, en la cual la Organización de las Naciones Unidas para la Educación, la Ciencia y la Cultura y el PNUD, junto con los gobiernos nacionales y locales, son los actores líderes de su seguimiento y cumplimiento.

Estos ODS están enmarcados en lo que actualmente se conoce como desarrollo humano sostenible y están interrelacionados al considerar que todos los problemas de las sociedades están interconectados y que, por tanto, para lograr un objetivo se requiere trabajar en los restantes.

En este orden de ideas, un elemento importante para el crecimiento económico y la reducción de la pobreza y el hambre es que las personas accedan a empleos duraderos, con remuneración suficiente para mantenerse a sí mismas y a sus familias, tanto en la edad productiva como en la vejez. En este sentido, el ODS \# 8 busca promover el crecimiento económico sostenido, inclusivo y sostenible, el empleo pleno y productivo y el trabajo decente para hombres y mujeres, a través de la estimulación del crecimiento económico sostenible, mediante el aumento de los niveles de productividad y la innovación tecnológica (PNUD, 2018). Por tanto, es imperativo el fomento de políticas que estimulen el espíritu empresarial y promuevan la creación de empleos suficientes en condiciones de libertad, igualdad y oportunidad, así como también de medidas tendientes a erradicar el trabajo forzoso, la esclavitud y el tráfico humano.

Para su seguimiento, se definieron doce objetivos junto con unas metas. De los 12 objetivos específicos, cinco están relacionados con empleos decentes y los restantes con crecimiento económico (excluyendo el objetivo 8.B, que se constituye como una apuesta de carácter mundial). La lista de estos ODS puede consultarse en PNUD Colombia (2021).

Son cinco las metas adoptadas por Colombia en cuanto a trabajo decente (PNUD, 2018). Estas están relacionadas con formalidad laboral, desempleo, actividades productivas de los jóvenes, trabajo infantil y seguridad en el empleo, respectivamente. Las siguientes son las metas sobre trabajo decente adoptadas:

- 8.3: promover políticas para apoyar la creación de empleo y el crecimiento de las em- 
presas. Meta nacional (MN): aumentar a 2030 la tasa de formalidad laboral al 60\%.

- 8.5: trabajo decente e igualdad de remuneración (MN: lograr a 2030 una tasa de desempleo del 6,8\%).

- 8.6: reducir el desempleo juvenil (MN: lograr a 2030 una tasa de ninis -población de 14 a 28 años de edad que no estudia ni trabajadel 15\%).

- 8.7: poner fin a la esclavitud moderna, la trata y el trabajo infantil (MN: reducir al 2030 la tasa de trabajo infantil al 6\%).

- 8.8: derechos laborales universales y entornos de trabajo seguros (MN: lograr al 2030 que el $48 \%$ de la población ocupada esté afiliada a una administradora de riesgos laborales).

Para su consecución, el gobierno nacional ha adoptado, entre otras, las siguientes estrategias y normatividades:

- Plan Nacional de Desarrollo (PND) 20142018: incluyó lineamientos de trabajo decente, especialmente en sus retos i) "Colombia equitativa y sin pobreza extrema", particularmente con el objetivo de reducir las brechas poblacionales y territoriales en materia de ingresos; ii) movilidad social para generar alternativas para crear empleos de calidad y acceder al aseguramiento ante la falta de ingresos y los riesgos laborales; y iii) seguridad, justicia y democracia para la construcción de paz con objetivo de fortalecer las instituciones para la promoción, respeto y protección de derechos. Esto sugiere que parte de las políticas públicas promoverían el trabajo decente (Departamento Nacional de Planeación -DNP-, 2015).

- Cinco pactos por el trabajo decente y empresas productivas propuestas por el Ministerio de Trabajo (MinTrabajo) en la Comisión de Concertación de Políticas Laborales y Salariales, los cuales son: i) proteger la vejez; ii) erradicación del trabajo infantil y peores formas, y protección al adolescente trabajador; iii) formalización laboral, protección social y asociatividad; iv) empleo como un servicio público; y v) calidad del trabajo. Estos pactos han sido trabajados por el equipo técnico del Ministerio y originaron una serie de documentos con recomendaciones para la promoción del empleo en el marco del trabajo decente a entes territoriales. Un ejemplo es el del Valle (Mintrabajo, 2015).

- PND 2018-2022: En el pacto por la equidad, se generaron unos objetivos trazadores y sus respectivas estrategias para promover el acceso a la protección social, la ubicación en puestos de calidad y mejorar la cualificación de las personas. Se tienen como metas crear 1,6 millones de empleos, reducir el desempleo al $7,9 \%$ y aumentar la formalidad hasta el 41,2\% para el 2022 (DNP, 2019).

Por su parte, los municipios, a través de sus concejos, han implementado acuerdos municipales y, a través de las alcaldías, planes locales de empleo para fomentar el trabajo decente ${ }^{3}$. Así mismo, las gobernaciones han legislado ordenanzas en el tema. Adicionalmente, algunas entidades no gubernamentales han desarrollado documentos destinados a las empresas y sectores económicos para que estos implementen estrategias de promoción de empleos decentes -es el caso por ejemplo, de la Fundación Ideas para la Paz (2014)-.

\section{Datos y metodología}

Lo que vino después en la literatura tras la definición de las dimensiones que fundamentan el trabajo decente, fue la forma de medirlo y de hacerle seguimiento. Frente a la posibilidad de expresar el trabajo decente a través de un único índice sintético, la ILO (2013) ha recomendado no hacerlo ya que esto implicaría ponderar la importancia de sus objetivos y dimensiones, desconocer la multidimensionalidad del concepto y olvidarse de lo que se busca principalmente con este: analizar y tomar medidas frente a la evolución en un territorio,

3 Es el caso, por ejemplo, de Medellín con el Acuerdo 64 de 2013 (Concejo de Medellín, 2013) y el Plan Local de Empleo y Bogotá a través del Decreto 380 de 2015 (Alcaldía Mayor de Bogotá, 2015). 
Sociedad y Economía N 43 (Mayo - Ago 2021) / e-ISSN: 2389-9050 / e10710914

¿Qué tan lejos está el ODS \# 8 para Colombia? Una década de medición del trabajo decente

Tabla 1. $\mathrm{N}^{\circ}$ de indicadores estadísticos propuestos en el estudio y los definidos por OIT por dimensión

\begin{tabular}{ccccccccccccc} 
Dimensión & 1 & 2 & 3 & 4 & 5 & 6 & 7 & 8 & 9 & 10 & 11 & Total \\
Estudio* & $13(4)$ & 6 & 4 & 1 & $2(1)$ & 2 & 4 & $3(1)$ & 2 & 2 & 0 & $39(6)$ \\
OIT & 11 & 7 & 5 & 2 & 5 & 4 & 8 & 4 & 10 & 5 & 11 & 72 \\
\hline
\end{tabular}

Nota: ${ }^{*}()$ Indica el $n^{\circ}$ de indicadores propuestos de la dimensión para el seguimiento al ODS \# 8

Fuente: elaboración propia.

en vez de comparar un país con otro. Teniendo en cuenta lo anterior, la OIT en 2013 propuso más de 80 indicadores, en su mayoría estadísticos y otros jurídicos. Varios de ellos, los principales, incorporan algunos ODM.

Lo que se presentó luego ha sido la adaptación de dichos indicadores al contexto y disponibilidad de las fuentes de información de las naciones. Es así como en este estudio, tomando como referencia la guía para productores y usuarios de indicadores (ILO, 2013) y el documento debate de la OIT (ILO, 2008), y las investigaciones de López (2020) y de Pineda et al. (2013), se proponen un total de 39 indicadores distribuidos en las primeras diez dimensiones del trabajo decente como se presenta en la Tabla 1.

Para su cálculo, se usaron principalmente los microdatos de la Gran Encuesta Integrada de Hogares (GEIH) del DANE para el periodo 20102019 (DANE, 2020) utilizando Stata. Para la dimensión 9 , en particular, se utilizó además la base de RLDatos de riesgos laborales ( $\mathrm{Fa}$ secolda, 2020), la cual reporta el número de empresas afiliadas, de trabajadores, accidentes, enfermedades y muertes calificadas en el trabajo, el promedio de trabajadores por empresa y las tasas de accidentes y muertes laborales. Para la dimensión 10, se empleó el sistema Sislab de la ENS (2020), el cual contiene cifras del censo sindical y de la dinámica de la contratación.

La metodología empleada incluye el reporte de los indicadores junto con un análisis intertemporal y comparaciones entre unidades geográficas, así como una revisión con enfoque de género. En algunos casos, se examinan promedios; en otros, tendencias y ampliación o reducción de brechas territoriales y de género. También se analiza el nivel de cumplimiento de los objetivos del ODS \# 8 en materia de em- pleo decente, teniendo en cuenta que solo 6 de los indicadores propuestos para medir el trabajo decente en este estudio, cuentan con una meta oficial en el marco de los ODS. Así mismo, se realizan algunas recomendaciones de política pública. En la Tabla A1 del Anexo se reporta la ficha técnica resumida de cada indicador (dimensión a la que pertenece, nombre y código OIT, definición, fórmula de cálculo y unidad de medida).

Las unidades geográficas de interés consideradas en este estudio son cuatro y cuentan con representatividad estadística: i) total de trece principales ciudades y sus áreas metropolitanas $^{4}$, ii) agregado nacional, iii) urbano nacional (cabeceras) y iv) rural nacional (centros poblados y rural disperso). Para el análisis con enfoque de género, se discriminan la mayoría de indicadores por sexo para el nivel nacional.

\section{Medición del trabajo decente en Colombia}

En esta sección, se presentan los principales resultados y hallazgos tras la estimación de los distintos indicadores por dimensión, así como algunas recomendaciones de política. Algunos indicadores no son presentados en gráfico o tabla por temas de extensión. Sin embargo, los indicadores laborales tradicionales y unos cuantos novedosos pueden consultarse a manera de imágen o en excel a través de la plataforma "Fuente de Información Laboral de Colombia (FILCO)" de Mintrabajo (2020).

4 Las cuales son: Bogotá, Medellín - Valle de Aburrá, Cali - Yumbo, Barranquilla - Soledad, Bucaramanga - Floridablanca - Girón Piedecuesta, Manizales - Villamaría, Pasto, Pereira - Dosquebradas - La Virginia, Ibagué, Cúcuta - Villa del Rosario - Los Patios - El Zulia, Villavicencio, Montería y Cartagena. 


\subsection{Dimensión \# 1: oportunidades de empleo}

Esta primera dimensión da cuenta de lo que tradicionalmente ha interesado a los hacedores de política: el tema de cantidades (vacantes, puestos de trabajo, oferta y demanda laboral) y algo de calidad del empleo (formalidad). Los resultados de esta dimensión evidencian que la problemática de cantidades y de calidad del mundo laboral sigue vigente en el país. En particular:

- Para todos los casos de interés (desagregaciones a nivel de territorio y de sexo), se identifica una forma de " $U$ " invertida en la tasa de ocupación, al igual que en la tasa de jóvenes de 14 a 28 años que ni estudian ni trabajan, mientras que en la de desempleo se registra una forma de "U". Lo que indica que al inicio de la década se registraba una tendencia deseable (entre el 2010 y el 2015), pero luego un comportamiento preocupante. La tasa promedio de desempleo de la década es del 9,9\%, registro inferior a la de 2018 y 2019 para el agregado nacional y las 13 ciudades. La meta ODS de la tasa de desempleo del $6,8 \%$ sería más difícil de alcanzar por parte de las mujeres (la tasa de 2019 es el doble de la meta), quienes en todo el periodo han registrado un mayor desempleo que los hombres. A nivel nacional, en el 2019, la distancia de la meta es de 3,7 puntos porcentuales (pp). En el 2015, cuando se definieron los ODS, la distancia era de 2,1 pp.

- Es de destacar la brecha importante entre hombres y mujeres en todos los indicadores a favor de los hombres. En el de ocupación, la diferencia es en promedio de $22,4 \mathrm{pp}$; en la tasa de desempleo, es de $-5,5 \mathrm{pp}$; en el de ninis es de $18,2 \mathrm{pp}$; en la informalidad, es de alrededor de 1 pp; en la tasa bruta de participación (TBP) es de 15,8pp y en la tasa global de participación (TGP) es de 21,1 pp.

- El desempleo golpea más a las mujeres (un promedio del $13 \%$ frente al 7,6\% de los hombres); a quienes cuentan con una escolaridad más alta especialmente a los que cuentan con educación media y superior (en el 2019, ambas superaron el $12 \%$ frente a un $6,3 \%$, registrada por quienes tienen a lo sumo básica primaria); y a los más jóvenes, en primer lugar a los que tienen de 18 a 28 años, seguido de los menores de edad.

- La informalidad en sus dos medidas registra una tendencia decreciente (Ver Tabla A1). Sin embargo, la meta ODS del $40 \%$ es considerablemente alta, considerando la tasa de decrecimiento anual histórica que registra, la cual sugeriría que para el 2030 la informalidad estaría cerca del 49\%. Mientras que en el 2010 en el agregado nacional, $64(71)^{5}$ de cada 100 ocupados eran informales, 9 años después pasó a 59 (63). La problemática de la informalidad registra mayor incidencia en la zona rural, en la cual, entre 8 y 9 ocupados de cada 10 son informales. La meta a 2018 de llegar a una tasa de formalidad del $52 \%$ no se logró.

- Siguen siendo los hombres quienes participan más en el mundo laboral, aunque dicha diferencia viene siendo constantemente menor, lo que evidencia la mayor participación de las mujeres en el empleo que viene presentándose en el mundo (Cárdenas, 2013).

- Los ocupados del país son, en su mayoría, obreros o empleados de empresas particulares, siguiéndole los cuentapropistas. No obstante, la participación de los primeros registra una tendencia decreciente: mientras que en el 2010 el $51,4 \%$ de los ocupados pertenecían a esta categoría, en el 2019 no supera el $40 \%$ y el promedio se ubica en un $38,6 \%$. En contraste, los cuentapropistas ganaron margen, pasando del $35,7 \%$ en 2010 al $40,6 \%$ en el 2019 , con un promedio de $42,8 \%$.

- Es en la zona rural del país donde se registra mayor porcentaje de trabajadores por cuenta propia y menor porcentaje de asalariados no agrícolas.

\subsubsection{Discusiones y recomendaciones}

La lectura de esta primera dimensión es insuficiente para dar conclusiones de si el mundo la-

5 Medición de la informalidad según la afiliación del ocupado tanto a salud como a pensión. 
Sociedad y Economía N 43 (Mayo - Ago 2021) / e-ISSN: 2389-9050 / e10710914

¿Qué tan lejos está el ODS \# 8 para Colombia? Una década de medición del trabajo decente

Tabla 2. Tasa de crecimiento en el $n^{\circ}$ de empresas generadoras de empleo formal Nacional: 2010-2016

\begin{tabular}{lrllllll} 
Porcentaje & 2010 & 2011 & 2012 & 2013 & 2014 & 2015 & 2016 \\
& $7,0 \%$ & $6,0 \%$ & $3,4 \%$ & $3,5 \%$ & $4,8 \%$ & $2,0 \%$ & $3,2 \%$ \\
& \multicolumn{8}{c}{ Fuente: cálculos propios, FlLCO (Mintrabajo, 2020). }
\end{tabular}

boral colombiano es o no decente, o al menos, si es de calidad o no. Pese a ello, la involución de los indicadores tradicionales laborales que se viene presentando desde el 2015 (desempleo y ocupación), el relativo estancamiento en indicadores "novedosos" (ninis) y en tradicionales (TGP y TBP), la decreciente pero aún alta informalidad laboral y empleo cuentapropista (especialmente en la zona rural) y las brechas territoriales y de género a favor de la zona urbana y hombres, respectivamente, dan cuenta que basta analizar esta dimensión para concluir que el trabajo en Colombia no es decente. Adicional a esto, las tres metas ODS circunscritas en esta dimensión (desempleo al $6,8 \%$; ninis al $15 \%$ y formalidad al $60 \%$ ) no se lograrían según el comportamiento de los últimos cinco años: entre otras realidades, el país no está generando suficientes puestos de trabajo que absorban la oferta laboral algo mayor que hace unos años. El incremento de las empresas que generan empleo formal en el país es insuficiente; incluso es el año 2010 el que registra la tasa de crecimiento más alta de los últimos años (ver Tabla 2). En este orden de ideas, es clave que desde el gobierno nacional se adopten políticas que mejoren el ambiente económico, alivios tributarios, acceso a créditos blandos y acompañamientos a nacientes empresas que les permitan surgir dentro de la formalidad.

\subsection{Dimensión \# 2: ingresos adecuados y trabajo productivo}

La tendencia de los indicadores en esta dimensión da cuenta de lo siguiente:

- El porcentaje de ocupados pobres, medido como la proporción de ocupados de hogares cuya línea de pobreza supera el ingreso familiar total per cápita del total de ocupados, registra una tendencia decreciente en todos los casos de interés. Mientras que, en el 2010, el $33 \%$ de los ocupados en el país eran pobres según la definición dada, 9 años después es el $21,3 \%$. Esto da muestra de un comportamiento positivo en los ingresos de los hogares: que, en cuanto se suman todos los recibidos en el hogar, los ingresos superan el parámetro frecuentemente usado para cuantificar la pobreza monetaria. Los resultados para las 13 ciudades son muy similares a los de la zona urbana, que son a propósito mejores que los registrados por la zona rural, para la cual no se registra una tasa superior del 20\%. Para el 2019, la diferencia entre la zona urbana y la rural es del 14,1 pp y la brecha promedio es de 15,8 pp. Lo positivo es que dicha brecha se ha venido reduciendo en el tiempo (Figura 1).

- Esta tendencia a la baja también se evidencia en la tasa de asalariados con bajos ingresos, estos son, los ocupados asalariados que devengan una remuneración inferior a las dos terceras partes de la mediana del ingreso según el territorio y año. Aquí se confirma la mejor situación en materia de ingresos que se vive en la zona urbana del país y la diferencia a favor de los hombres (Figura 2).

- El ingreso laboral promedio por hora trabajada ha registrado siempre un incremento en todas las unidades geográficas y en hombres como en mujeres. Sin embargo, los hombres siempre han sido mejor remunerados, situación explicada en buena parte por la condición de madres de las mujeres ${ }^{6}$. Adicionalmente, quienes residen en la zona urbana del país también son mejor pagos.

- Considerando el efecto inflacionario en los ingresos, el salario promedio real (con año como base el 2018) confirma lo mencionado anteriormente, exceptuando que la tasa de crecimiento del salario medio entre un año y el otro no siempre ha sido positiva. En particular, entre el 2012 y 2011 los salarios en todas las unidades geográficas y en hombres y en mujeres cayeron

6 Hay en la literatura evidencia de que los ingresos durante la vida laboral de las mujeres son más bajos que el de los hombres debido a la "pena" de la maternidad (The Economist, 2019). 
Figura 1. Tasa de ocupados pobres por unidad geográfica y sexo: 2010-2019

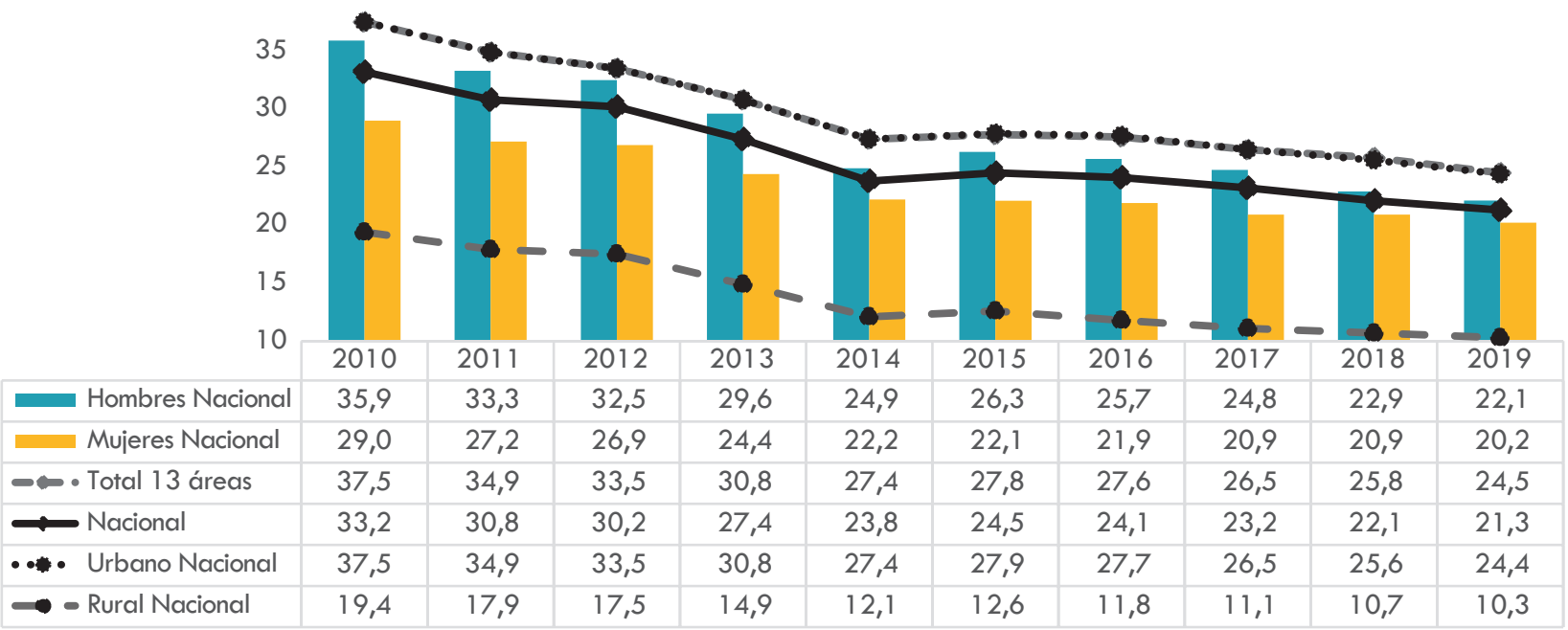

Fuente: elaboración propia con información de GEIH (DANE, 2020).

Figura 2. Tasa de asalariados con bajos ingresos por unidad geográfica y sexo: 2010-2019

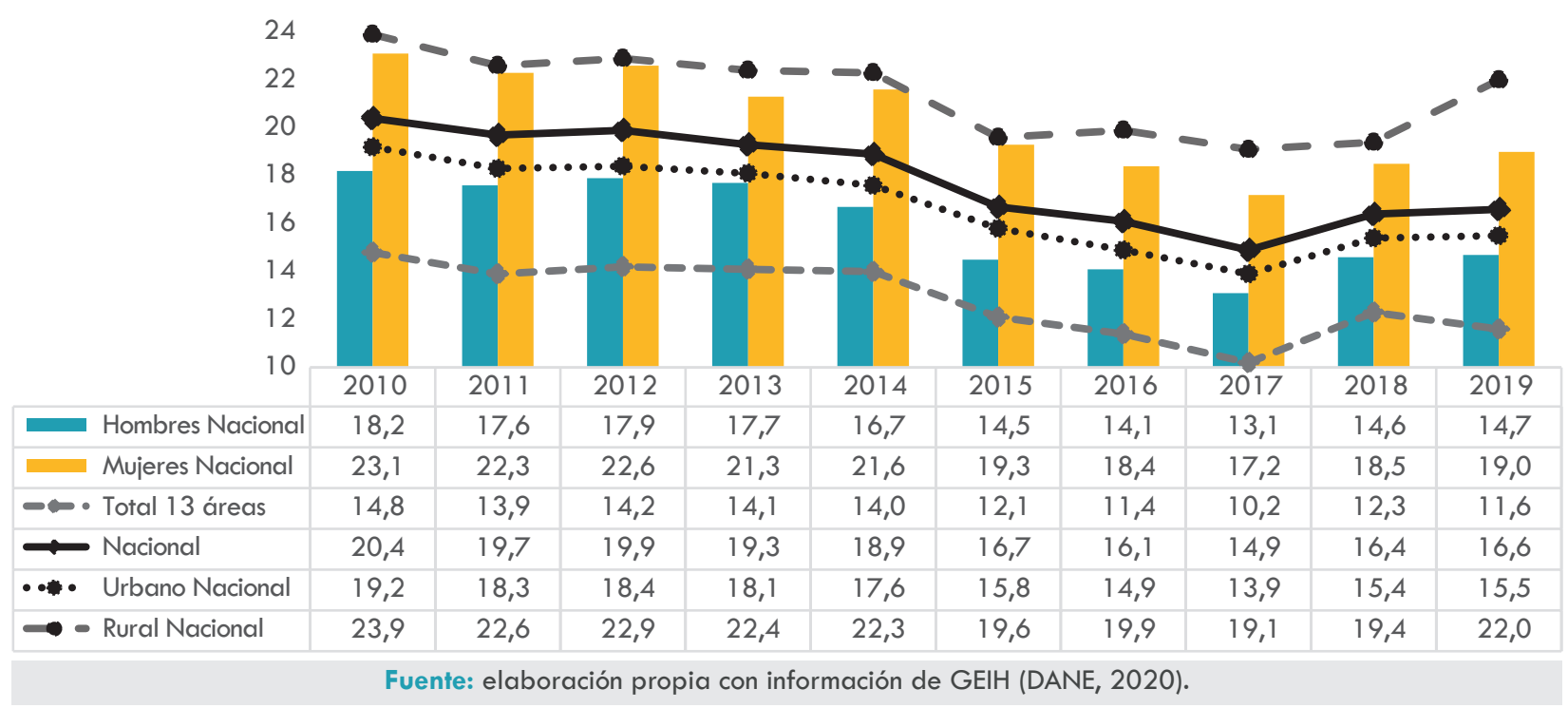

(al menos un 1,5\%), al igual que entre el 2014 y 2015 (con una caída de al menos el 3,3\%), lo cual indica entonces la pérdida de capacidad adquisitiva de los ocupados del país.

- Para todo el periodo, el porcentaje del salario mediano según el territorio siempre ha sido superior al salario mínimo mensual vigente a nivel país, en la zona urbana, para las 13 principales ciudades y para los hombres. Dicho porcentaje ha sido creciente en el caso de las 13 ciudades y el agregado nacional, no así si se considera la zona urbana. En el caso de las mujeres, el promedio del porcentaje de participación del salario es de $97,3 \%$ (con tendencia alcista) y, para el caso de la zona rural, es del $61,2 \%$, también con comportamiento creciente.

- La dependencia económica, entendida como el porcentaje de hogares en los que por cada integrante ocupado hay más de 3 integrantes (1:3), ha registrado una tendencia decreciente. Mien- 
tras que, en el 2010, el 31,4\% de los hogares colombianos eran dependientes económicos, nueve años después es el 27,6\% La situación ha sido mejor en las 13 ciudades y en la zona urbana del país.

\subsubsection{Discusión y recomendaciones}

La tendencia a la baja del porcentaje de ocupados pobres y el comportamiento esperado de los ingresos laborales son hechos positivos para la condición decente del trabajo en Colombia. Los resultados ratifican la reducción de la pobreza monetaria que ha vivido el país (OCDE, 2019), la cual pasó, según cifras del DANE (2019), del $37,2 \%$ (nacional), 33,3\% (urbano), 49,7\% (rural), en el 2010 , al $27 \%, 24,4 \%$ y $36,1 \%$ para el 2018 , respectivamente. En términos generales, los resultados de esta dimensión dan cuenta de la evolución positiva que ha presentado el empleo en el agregado hacia su situación deseable de decente. Sin embargo, nuevamente se perciben peores condiciones para las mujeres y los residentes de la zona rural: sus ingresos laborales se han mantenido durante la década por debajo al registrado por los hombres y la zona urbana del país. En este sentido, dadas las brechas territoriales y de género, la conclusión es la misma: como hay desigualdades, el empleo en Colombia en materia de ingresos no es decente.

En este sentido, el reto más importante en esta dimensión es reducir las brechas mencionadas.
Para ello, la política pública debería ir encaminada a mejorar la cualificación de las mujeres y a transitar desde la situación de subempleabilidad que sufren ellas (en sus tres formas: por ingresos, competencias y horas laboradas) hacia una de mayores horas de trabajo, por ejemplo, flexibilizando los contratos laborales mediante técnicas de tipo virtualidad laboral o a distancia, cuando las mujeres se encuentren en maternidad.

\subsection{Dimensión \# 3: tiempo de trabajo decente}

Los resultados en esta dimensión indican:

- La tasa de ocupados que laboran más de las 48 horas legales a la semana registró a lo largo de la década una tendencia bajista. Sin embargo, esta es relativamente alta. Mientras que para el agregado nacional el $36 \%$ de los ocupados tenían un trabajo excesivo en el 2010, en el 2019 este porcentaje bajó al 28\%, aunque la mayor caída la presentaron las 13 ciudades (con 7,2 pp de reducción). De igual forma, son los hombres quienes más superan la jornada de 48 horas, al igual que los ocupados residentes en la zona urbana del país (Figura 3). Son las mujeres las que trabajan en su mayor parte menos de 40 horas justificando así sus menores rentas.

- La jornada laboral semanal en promedio en la década fue de 44,9 horas a nivel nacional, infe-

Figura 3. Tasa de tiempo de trabajo excesivo por unidad geográfica y sexo: 2010-2019

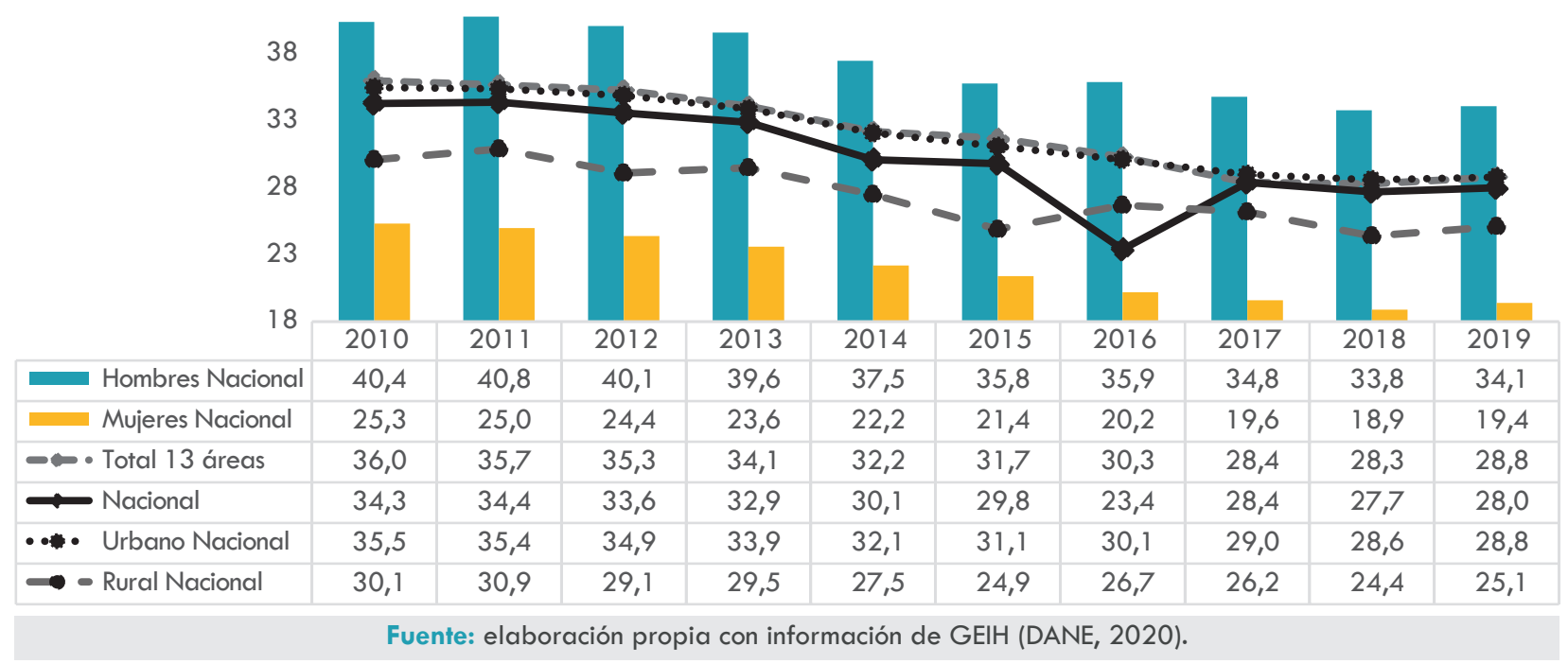


rior a la registrada por las 13 ciudades $(46,7)$. Adicionalmente, y confirmando lo mencionado en el ítem anterior, los hombres trabajan más horas a la semana en promedio que las mujeres (al menos 8 horas más). En este indicador, también se observa una tendencia ligeramente bajista en el tiempo.

- La tasa de subempleo objetivo se entiende como la situación de quienes tienen el deseo y han hecho una gestión para materializar su aspiración y están en disposición de efectuar el cambio de empleo, debido a un subempleo por insuficiencia de horas o por empleo inadecuado, ya sea por ingresos menores al salario de reserva o por competencias (DANE, 2018). Esta tasa registró una tendencia a la baja hasta el 2016. A partir del 2017 , se presenta un incremento en todos los casos de interés, aunque no alcanzando los valores de inicio de década. A 2019 , el subempleo objetivo en el país se ubica en $12 \%$. Y son las mujeres quienes se sienten más subempleadas (la brecha promedio es de $0,8 \mathrm{pp}$ ). De forma similar, son los ocupados de la zona urbana quienes más se consideran en situación de subempleo objetivo, aunque para este caso las brechas son más significativas (en promedio de 3,4 pp).

\subsubsection{Discusión y recomendaciones}

La dimensión de trabajo decente que no sería considerada dentro del análisis tradicional de los mercados laborales y que tampoco sería tomada en cuenta en un estudio sobre la calidad del empleo, brinda evidencia de los menores ingresos laborales de las mujeres por su mayor situación de subempleo. No obstante, que en el país y, en promedio, 3 de cada 10 ocupados laboren más de la jornada legal, indica que un porcentaje importante de los empleados de Colombia no cuentan con aquel tiempo de vida dedicado a la salud, a la recreación, al deporte, a la familia y al descanso. Ahora, esto lleva a preguntarse si ese tiempo extra de trabajo es o no remunerado. Con base en la GEIH, no es clara la situación: por un lado, se tiene que, en promedio, 9 de cada 10 ocupados con contrato (verbal o escrito) en el país no recibieron ingresos por concepto de horas extras. Por otro lado, en promedio, 4 de cada 100 ocupados con contrato trabajaron la semana pasada horas extras remuneradas. Con esta importante diferencia estadística no es posible concluir.

En resumen, aquí se hace necesario entonces examinar bien el nivel de satisfacción de los trabajadores colombianos con su empleo para tomar medidas que mejoren la situación del subempleo en el país e impactar positivamente el tiempo que se le dedica a otras actividades.

\subsection{Dimensión \# 4: conciliación del trabajo, la vida familiar y la vida personal}

En consonancia con lo anterior, esta dimensión examina las relaciones existentes entre el trabajo y la vida familiar y personal de los trabajadores $y$, para ello, se debe analizar en detalle el caso de las mujeres, quienes usualmente ejercen actividades no remuneradas (cuidado de niños, enfermos, ancianos, oficios del hogar, etc.) (Anker et al., 2003).

Para aproximarnos a esta dimensión, se propone ${ }^{7}$ la tasa de tiempo no remunerado (TNR) frente al tiempo total de los ocupados (Figura 4).

Según los resultados, se ha presentado relativa estabilidad en el indicador $\mathrm{y}$, en promedio y a nivel nacional, el $27,6 \%$ del tiempo total de los ocupados se destina a actividades no remuneradas ${ }^{8}$. Adicionalmente, en toda la década, los porcentajes registrados para las 13 ciudades son menores al nacional, al igual que el urbano nacional. No es el caso de las mujeres: para este grupo poblacional, el porcentaje dedicado a actividades no

7 En la literatura, otros indicadores estadísticos que se proponen son: i) porcentaje de ocupados con horario laboral atípico y ii) protección de maternidad. Entre los indicadores legales se pueden usar: i) tasa de beneficios y tiempos de licencia de maternidad a la madre y padre (ILO, 2013; Anker et al., 2003).

8 Del capítulo L de la GEIH se emplea la respuesta en horas a la semana a la pregunta: "Adicional a las actividades que me informó haber realizado la semana pasada, cuáles de las siguientes labores no remuneradas hizo". Aquí se incluyen labores del campo, oficios en el hogar y por fuera de este, cuidado de personas, actividades comunitarias, etc. 
Figura 4. Tasa de TNR con respecto al total por unidad geográfica y sexo: 2010-2019

\begin{tabular}{|l|l|l|l|l|l|l|l|l|l|}
\hline & & & & & \\
\hline
\end{tabular}

Fuente: elaboración propia con información de GEIH (DANE, 2020).

remuneradas siempre ha sido superior, con un máximo de $42,9 \%$ registrado en 2012 y 2013 , y un mínimo de $39,5 \%$ ocurrido en 2016 . Y, en promedio, la tasa de actividades no remuneradas es del $41,8 \%$, frente a la de los hombres ubicada en el 16\%. La situación negativa también la perciben los ocupados en zonas rurales del país, con un indicador promedio de $32,2 \%$.

\subsubsection{Discusión y recomendaciones}

Con el indicador propuesto, es posible identificar la carga en tiempo no remunerado que tienen los ocupados colombianos, lo que incide directamente en la menor posibilidad de tener actividades adicionales con remuneración, teniendo en cuenta que en este indicador no se incluye el tiempo dedicado a la familia, a la vida personal o al descanso. Enlazando la dimensión anterior y esta, se hace importante reflexionar sobre la cobertura que tienen los programas de bienestar humano que tienen las empresas y la normatividad que las rige. De igual forma, es de revisar la discriminación que sufren las mujeres por ser las que dedican más de su tiempo a actividades no remuneradas.

\subsection{Dimensión \# 5: trabajo que debería ser abolido}

Economías con empleos decentes garantizan la erradicación de trabajo forzoso, discriminatorio e infantil. Al respecto, la meta ODS de trabajo in- fantil es del 6\%. Según los resultados encontrados, este objetivo ya ha sido logrado únicamente a nivel de las 13 principales ciudades que, en promedio, registran una tasa de trabajo infantil para menores de 5 a 17 años del $5 \%$ y, desde el 2015 , las mujeres vienen registrando un indicador inferior al $6 \%$ y con tendencia decreciente. Dicha tendencia positiva se identifica en todos los casos. Como complemento de este indicador, se calcula el mismo, pero para la población de 10 a 17 años (tomando como edad inicio la que define a la PET en el país, según el DANE) que labora a la semana más de 15 horas. Como es de esperarse, los valores de este segundo indicador son, en 41 de 42 casos, inferiores a los del primero. Las mujeres, los ocupados en la zona urbana del país y los residentes de las 13 ciudades han reportado siempre una tasa menor a la meta a 2030. A nivel nacional la tendencia es positiva ya que es decreciente, llegando en 2019 al 4,3\% para el segundo indicador y a 0.1 pp de la meta ODS. Finalmente, son los niños los más afectados.

\subsubsection{Discusión y recomendaciones}

El comportamiento decreciente en todos los casos de interés de ambos indicadores refleja el mayor avance hasta el momento del país en materia de trabajo decente. De las metas ODS es la que actualmente y de manera parcial se cumple y es de esperar que se logre al 2030. Es importante, entonces, que la política pública nacional continúe facilitando el acceso de los niños y jóvenes al 
sistema educativo mediante la otorgación de becas y créditos blandos en el caso de los estudios postsecundarios y reclutamiento de los niños desescolarizados. Así mismo, trabajar por el fortalecimiento del sistema de inspección, control y vigilancia de Mintrabajo para reducir aún más el trabajo infantil junto con el forzoso. También estar verificando la necesidad o no de replantear la estrategia nacional para prevenir y erradicar las peores formas de trabajo infantil y proteger al joven trabajador (Comité Interinstitucional Nacional, 2008) y el programa "Trabajar no es tarea de niños". También se hace importante mantener el Sistema de Información Integrado para el Registro y la Erradicación del Trabajo Infantil y sus Peores Formas (SIRITI).

\subsection{Dimensión \# 6: estabilidad y seguridad del trabajo}

Un trabajo decente es estable para que el trabajador se sienta seguro y tranquilo en él; que, en el país, 5 de cada 10 ocupados no cuenten con contrato laboral y que, de estos, 3 sean verbales, da cuenta de la alta inestabilidad e inseguridad que tienen los colombianos en sus empleos, condiciones asociadas a informalidad y mala calidad de los mismos.

Con base en los indicadores propuestos para esta dimensión, la tasa de trabajo precario, entendida como la proporción de la población ocupada que vive una situación laboral caracterizada por inseguridad, incertidumbre y falta de garantías en su trabajo, como es no tener un contrato, que este sea verbal o a término fijo, o que haya alguna empresa intermediaria en la contratación, viene registrando una tendencia decreciente en todos los casos de interés (Figura 5). No obstante, la tasa supera el $70-80 \%$, indicando que, en promedio, 8 de cada 10 ocupados tienen un empleo precario según la definición expuesta, coherente con la alta informalidad diagnosticada anteriormente. La situación es más preocupante en la zona rural, en donde la tasa media es del 93,8\% -y la brecha con el resto de casos es en promedio de 12 pp-; siguiéndole el registrado por los hombres (82\%) y el agregado nacional $(81,7 \%)$.

En cuanto a la duración de los contratos, la mayor antigüedad en todo el periodo la registra la zona rural del país, cuyo promedio, si bien es oscilante, se ubica en 103 meses, siguiéndole el registro de los hombres con un promedio de 88 meses y el agregado nacional con 79 . Con respecto a las mujeres, la diferencia con los hombres es en promedio de alrededor de 2 años, indicando entonces que las mujeres son quienes presentan una mayor inestabilidad en el empleo.

\subsubsection{Discusión y recomendaciones}

La inestabilidad de los empleos asociada con la informalidad refuerza la discusión planteada en la primera dimensión. El apoyo a las empresas formales y garantizar un buen ambiente económico son puntos clave para que en esta dimensión se siga con la tendencia decreciente de los empleos precarios. Así mismo, estrategias tendientes a promover la garantía de los derechos laborales.

\subsection{Dimensión \# 7: igualdad de oportunidades y trato en el empleo}

El trabajo decente, como ya se mencionó, necesariamente incluye el enfoque de género, por lo que se debe hablar sobre igualdad y trato en el mundo laboral. En este sentido, los indicadores de esta dimensión dan cuenta de la brecha laboral, tanto en salarios como en condiciones de trabajo, que han vivido las mujeres, al menos en esta última década, en el país.

El primer indicador propuesto mide la segregación ocupacional por sexo a través del conocido Índice de Duncan ${ }^{9}$, que evidencia la discriminación en contra de las mujeres, en la medida en que expresa la tradicional división sexual del trabajo, donde se subvaloran las actividades de tradición doméstica o que provienen y han sido desarrolladas por el trabajo no remunerado de la mujer. Los resultados indican que, a nivel nacional, el índice siempre ha estado por encima del resto de casos y su promedio es de 0,56; siguiéndola la zona rural con 0,52 . Es en las 13 ciudades donde se podría decir que existe una

9 El comportamiento deseado de este indicador es que se aproxime a cero indicando así una distribución exactamente igualitaria entre hombres y mujeres (Duncan y Duncan, 1995). 
Sociedad y Economía N 43 (Mayo - Ago 2021) / e-ISSN: 2389-9050 / e10710914 ¿Qué tan lejos está el ODS \# 8 para Colombia? Una década de medición del trabajo decente

Figura 5. Tasa de trabajo precario por unidad geográfica y sexo: 2010-2019

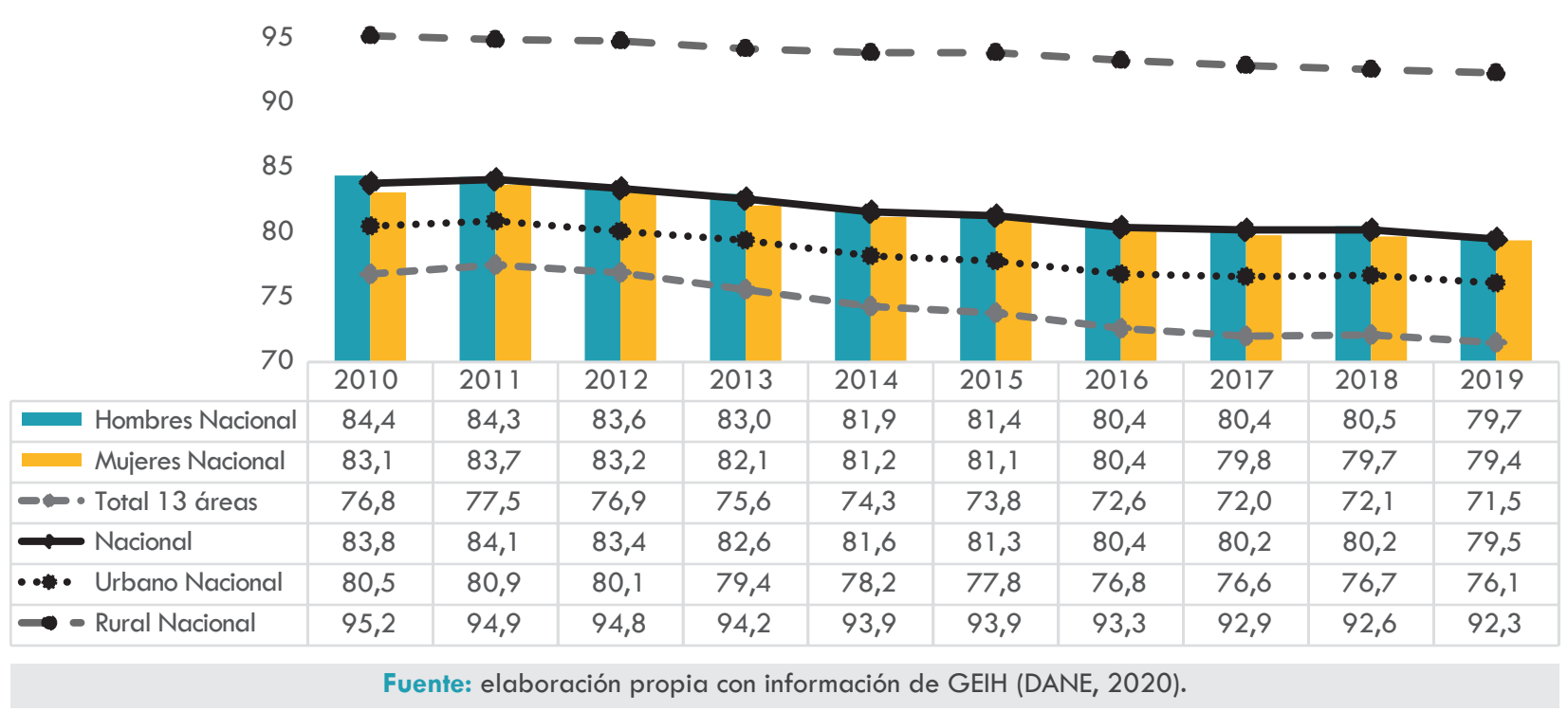

Figura 6. Índice de Duncan por unidad geográfica: 2010-2019

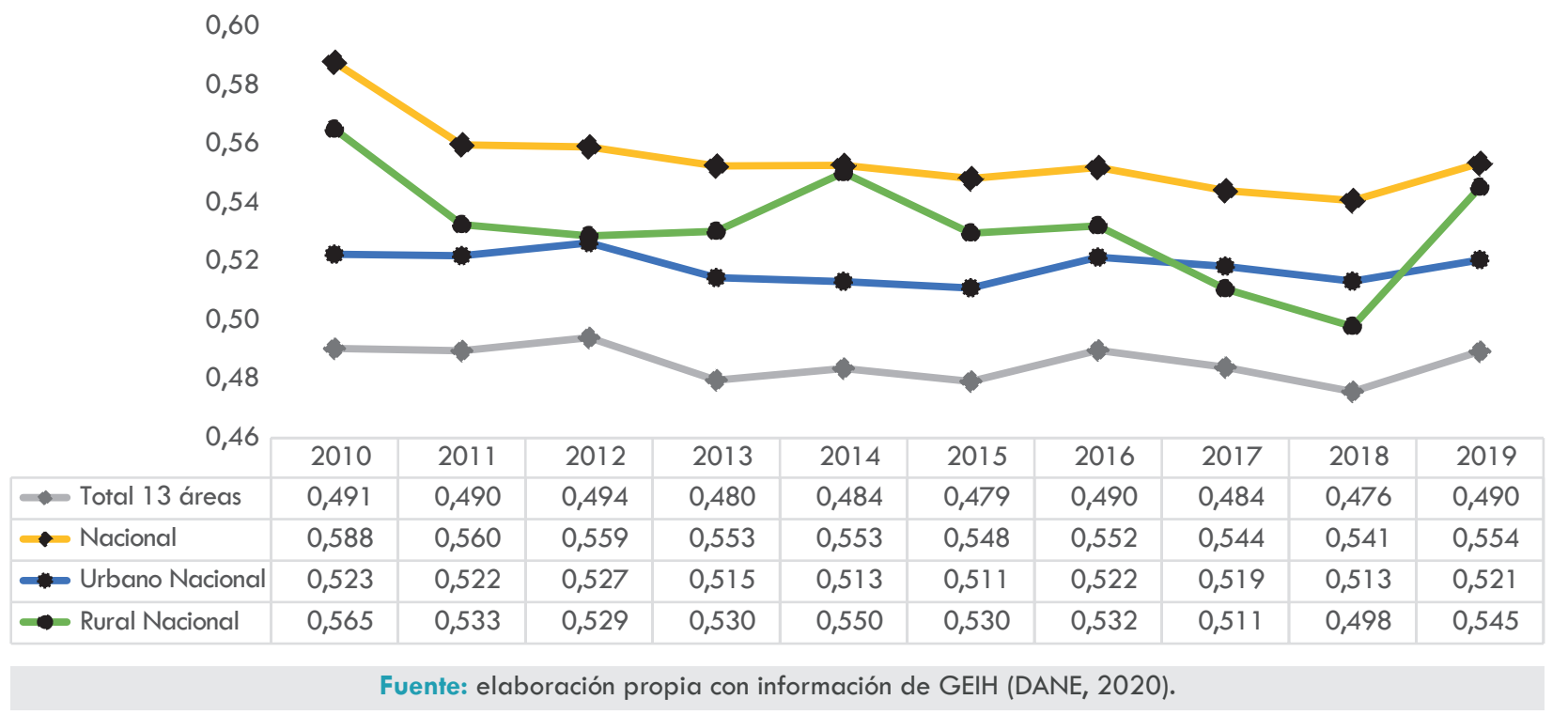

menor discriminación ocupacional hacia las mujeres, con un promedio de 0,49 (Figura 6).

A nivel de ingresos, en casi todos los casos de interés, la brecha salarial (entendida como la diferencia entre el salario total promedio por hora laborada, del primer y segundo empleo, entre los hombres y el de las mujeres) ha estado a favor de los hombres. De manera más significativa para las 13 ciudades, aunque con tendencia bajista, que también se presenta en el urbano nacional. Para el nacional, se tiene un promedio de 701 pesos de diferencia entre los salarios totales por hora entre hombres y mujeres, que representa entre un 10\% y un $20 \%$ del total del salario-hora.

En cuanto a la brecha en la jornada laboral, también se evidencia que las mujeres, en promedio, laboran menos que los hombres, y dicha diferencia es más significativa en la zona rural. Finalmen- 
te, en el país y en los últimos años, cerca de 4 de cada 10 ocupados en cargos directivos son mujeres.

\subsubsection{Discusión y recomendaciones}

Toda política dirigida a evolucionar el mundo laboral hacia una condición de empleos decentes, debe sustentarse en información y evidencia rigurosa discriminada por sexo y territorio, de tal forma que tenga en cuenta la discriminación que sufren las mujeres y quienes residen en la zona rural del país. Es importante, también, promover campañas tendientes a garantizar el trato igualitario.

\subsection{Dimensión \# 8: entorno de trabajo seguro}

RLDatos de Fasecolda (2020) registró, en el 2019, la tasa de accidentes laborales más alta en toda la década (8\%), a pesar de que, desde el 2012, se viene registrando una caída persistente en la misma (ver Tabla 3). En cuanto a la tasa de enfermedad laboral, esta ha estado en el orden del $0,1 \%$.

En esta dimensión también interesa conocer la proporción de ocupados afiliados al sistema de riesgos laborales. Según los resultados, la tendencia en todos los casos de interés durante la década fue creciente. Sin embargo, a 2019 aún faltan 10,5 pp a nivel nacional para alcanzar la meta ODS de $48 \%$ para el 2030 . De acuerdo con la tasa media de crecimiento del $3 \%$ para el agregado nacional, la meta se lograría entre el 2027 y 2028 . A nivel de sexo no hay diferencias significativas, pero sí a nivel de zona urbano-rural, en donde hay una diferencia a favor de la zona urbana en promedio de 27,6 pp.

\subsubsection{Discusión y recomendaciones}

Es importante seguir cubriendo a los trabajadores del país con el sistema de riesgos laborales, para asegurarles un entorno de trabajo seguro, decente, y enfocado en los trabajadores rurales, quienes son los que están en mayor riesgo en sus trabajos. En la zona urbana del país, es en donde más se ha avanzado, no solo porque se ha venido aumentando de manera constante la cobertura, sino que también se ha caracterizado por no diferenciar entre hombres y mujeres. De igual manera, el gobierno nacional, a través de Mintrabajo, debe fortalecer el sistema de inspección, vigilancia y control para reducir los accidentes y muertes en el trabajo. Lo bueno es que, de los ODS, este sería uno de los más alcanzables en materia de trabajo decente.

\subsection{Dimensión \# 9: seguridad social}

Los resultados en esta dimensión evidencian la falta de cubrimiento del sistema de pensiones en el país, por lo que da cuenta de la condición de empleos no decentes que caracteriza el mundo laboral colombiano. La situación para el 2019 es muy similar a lo registrado al inicio de la década. Para el agregado nacional, por ejemplo, en el 2010 , el $26,5 \%$ de los adultos en edad de jubilación eran beneficiarios de

\begin{tabular}{|c|c|c|c|c|c|c|c|c|}
\hline Año & $\begin{array}{c}\mathbf{N}^{\circ} \\
\text { Empresas }\end{array}$ & $\begin{array}{c}\mathbf{N}^{\circ} \\
\text { Trabajadores }\end{array}$ & $\begin{array}{c}\mathbf{N}^{\circ} \\
\text { Accidentes }\end{array}$ & $\begin{array}{c}\mathbf{N}^{\circ} \\
\text { Enfermedades } \\
\text { laborales }\end{array}$ & $\begin{array}{c}\text { N. }{ }^{\circ} \\
\text { Muertes }\end{array}$ & $\begin{array}{l}\text { Promedio de } \\
\text { empleados por } \\
\text { empresa }\end{array}$ & $\begin{array}{c}\text { Tasa de } \\
\text { accidentes (\%) }\end{array}$ & $\begin{array}{c}\text { Tasa de } \\
\text { enfermedad (\%) }\end{array}$ \\
\hline 2010 & 438.083 & 6.813 .664 & 450.564 & 8.902 & 691 & 16 & 6,6 & 0,13 \\
\hline 2011 & 491.056 & 7.499 .489 & 555.479 & 8.277 & 693 & 15 & 7,4 & 0,11 \\
\hline 2012 & 557.377 & 8.430 .802 & 659.170 & 10.053 & 678 & 15 & 7,8 & 0,12 \\
\hline 2013 & 607.957 & 8.271 .920 & 622.486 & 9.483 & 708 & 14 & 7,5 & 0,11 \\
\hline 2014 & 595.066 & 8.936 .937 & 688.942 & 9.710 & 569 & 15 & 7,7 & 0,11 \\
\hline 2015 & 644.011 & 9.656 .829 & 723.696 & 9.583 & 566 & 15 & 7,5 & 0,1 \\
\hline 2016 & 688.107 & 10.039 .533 & 701.696 & 10.572 & 607 & 15 & 6,9 & 0,11 \\
\hline 2017 & 743.449 & 10.237 .811 & 660.110 & 9.692 & 568 & 14 & 6,5 & 0,09 \\
\hline 2018 & 805.737 & 10.487 .600 & 645.119 & 10.450 & 573 & 13 & 6,2 & 0,1 \\
\hline 2019 & 839.016 & 9.655 .505 & 776.078 & 8.636 & 492 & 12 & 8,0 & 0,09 \\
\hline
\end{tabular}


pensión de vejez; nueve años después, dicho porcentaje se ubicó en $24,9 \%$. La zona rural es la más crítica, pues alrededor de 7 de cada 100 adultos mayores cuentan con pensión, mientras que en la zona urbana el promedio es de $29,4 \%$. Las mujeres nuevamente registran una desventaja: la brecha es de 9,9 pp, en promedio, exceptuando el 2010 donde la diferencia entre hombres y mujeres fue de menos de 2 pp.

Para el caso de los cotizantes a pensión, no hay diferencias significativas por sexo, pero, como en el caso anterior, sí es determinante la zona donde se reside. Mientras que en la zona urbana la tasa promedio es de $36,3 \%$; a nivel rural es de $11,9 \%$. No obstante, se registra una deseable tendencia alcista permanente en todos los casos de interés desde el 2010. En el 2019 , se tiene que 34 de cada 100 personas de la PEA, cotizan en un fondo de pensiones, situación que, si bien es mejor que hace 9 años, es aún deficiente respecto al ideal y para considerar al mundo laboral colombiano como decente (Figura 7).

\subsubsection{Discusión y recomendaciones}

El gobierno nacional con su ministerio de trabajo debe poner sus ojos en la zona rural del país, que según los hallazgos, es la más alejada de la concepción de trabajo decente en el marco de seguridad social. El sistema de inspección, vigilancia y control puede servir para esto, así como leyes especiales para los adultos mayores junto con una necesaria reforma pensional.

\subsection{Dimensión \# 10: diálogo social y representación de empleadores y trabajadores}

De acuerdo con los datos del sistema Sislab de la ENS, sintetizados en la Tabla 4, alrededor de 4 de cada 100 ocupados en el país está afiliado a un sindicato, cifra que se ha mantenido constante entre el 2013 y 2017 . En este último, se registran 5.523 sindicatos, un 1,4\% más que en el 2016. En este orden de ideas, se puede concluir que, en las relaciones laborales que ocurren en el país, el sindicalismo es marginal dadas las bajas cifras.

En cuanto a los convenios colectivos (convenciones, pactos y contratos sindicales) que se negocian cada año en el país, de acuerdo son Sislab, son reducidos y confirman así, el conocimiento popular de que Colombia es uno de los países donde resulta más difícil ejercer el derecho a la libertad sindical, a pesar de estar amparado en la Constitución (Asamblea Nacional Constituyente, 1991, Art. 2).

Figura 7. Tasa de cotizantes a fondos de pensiones por unidad geográfica y sexo: 2010-2019

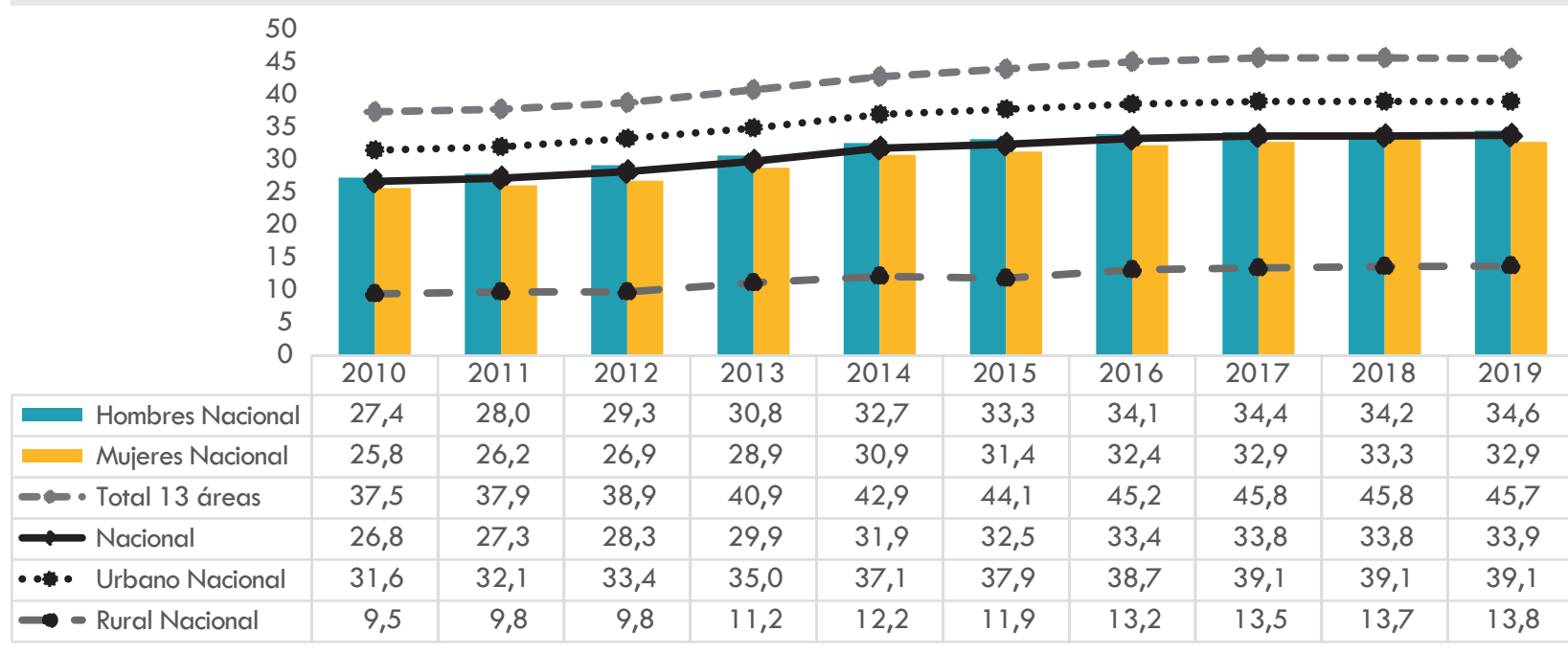

Fuente: elaboración propia con información de GEIH (DANE, 2020). 
Sociedad y Economía N 43 (Mayo - Ago 2021) / e-ISSN: 2389-9050 / e10710914

Silvio Fernando López-Mera

Tabla 4. Convenciones, pactos y cobertura de la contratación colectiva Nacional: 2013-2017

\begin{tabular}{|c|c|c|c|c|c|c|c|c|c|c|c|c|c|c|c|}
\hline \multirow{2}{*}{$\begin{array}{c}\text { Clase de } \\
\text { Sindicato (S) }\end{array}$} & \multicolumn{3}{|c|}{2013} & \multicolumn{3}{|c|}{2014} & \multicolumn{3}{|c|}{2015} & \multicolumn{3}{|c|}{2016} & \multicolumn{3}{|c|}{2017} \\
\hline & $\mathbf{N}^{\circ}$ & Afiliados & Tasa de S. & $\mathbf{N}^{\circ}$ & Afiliados & Tasa de S. & $\mathbf{N}^{0}$ & Afiliados & Tasa de S. & $\mathbf{N}^{\circ}$ & Afiliados & Tasa de S. & $\mathbf{N}^{\circ}$ & Afiliados & Tasa de S. \\
\hline S de gremio & 2.124 & 488.098 & $2,3 \%$ & 2.309 & 496.055 & $2,3 \%$ & 2.414 & 501.175 & $2,3 \%$ & 2.520 & 506.352 & $2,3 \%$ & 2.547 & 507.329 & $2,3 \%$ \\
\hline S. de empresa & 1.571 & 223.807 & $1,1 \%$ & 1.710 & 228.863 & $1,1 \%$ & 1.822 & 233.198 & $1,1 \%$ & 1.863 & 238.401 & $1,1 \%$ & 1.885 & 239.239 & $1,1 \%$ \\
\hline S. de industria & 629 & 243.259 & $1,2 \%$ & 753 & 261.187 & $1,2 \%$ & 863 & 265.277 & $1,2 \%$ & 939 & 274.606 & $1,2 \%$ & 960 & 275.635 & $1,2 \%$ \\
\hline S. oficios varios & 60 & 4.050 & $0,0 \%$ & 117 & 6.045 & $0,0 \%$ & 130 & 6.500 & $0,0 \%$ & 127 & 6.395 & $0,0 \%$ & 131 & 6.561 & $0,0 \%$ \\
\hline Total & 4.384 & 959.214 & $4,6 \%$ & 4.889 & 992.150 & $4,6 \%$ & 5.229 & 1.006 .150 & $4,6 \%$ & 5.449 & 1.025 .754 & $4,6 \%$ & 5.523 & 1.028 .764 & $4,6 \%$ \\
\hline
\end{tabular}

\section{Conclusiones}

El mundo laboral colombiano está lejos de ser considerado como decente, a la luz de la estimación para el periodo 2010 a 2019 de 39 indicadores estadísticos distribuidos en las primeras diez dimensiones que definen la nueva concepción del empleo: el trabajo decente que, como se mostró en la sección de resultados, va más allá de empleos suficientes para la fuerza laboral y de empleos de calidad, pues pensar en trabajos decentes es también tener en cuenta a las familias, a los desempleados y jubilados, la vida personal de la población y el trato igual sin discriminación; no solo a los ocupados. En este sentido, en 2019 Colombia está muy lejos de lograr el ODS \# 8.

Esto porque los avances en materia de cantidad en el mercado laboral, es decir, reducción del desempleo y aumento de la ocupación que se venía presentando hasta mitad de la década, se han ido perdiendo desde los últimos cinco años. En este sentido, el caso del ODS de reducir el desempleo en 2030 a 6,8\%, dada la tendencia de los últimos cinco años no se alcanzaría. Y si se tienen en cuenta los efectos negativos, que si bien aún no han sido estimados pero se cree que serán importantes y de largo plazo en la economía mundial, de la emergencia sanitaria por la pandemia del COVID-19 sobre el empleo y en la economía, el panorama deseado en el marco de la Agenda 2030 estaría caracterizado por el incumplimiento de varias metas de los ODS.

Adicionalmente, en el tema de calidad laboral, medido usualmente a través de la informalidad y nivel de ingresos del empleo, si bien los indicadores muestran una tendencia deseable (al alza), aún se está considerablemente lejos de la meta de tener una formalidad laboral del $60 \%$. Según la tendencia de esta última década, para el 2030 se tendría una informalidad cercana al $55 \%$.

Ahora, en cuanto a indicadores por género, se encuentra que las mujeres de manera consistente siempre han estado en una situación de desventaja en el mundo laboral, tanto en aseguramiento a los sistemas de salud, pensión y riesgos laborales, como en salarios y en condiciones contractuales. Similar fenómeno sucede entre la zona urbana y rural: la ruralidad en Colombia cuenta con un mundo laboral no decente y está más lejos de lograr los ODS a 2030.

Considerando la tasa de cambio de los últimos años, de los indicadores definidos por Colombia para monitorear el cumplimiento de los ODS concernientes a empleo decente, se puede concluir que, a nivel nacional, la meta de trabajo infantil ya fue alcanzada (y así se mantendría para el 2030) y la de afiliación a riesgos laborales se podría lograr a 2030. No obstante, a nivel de municipios y departamentos esto no necesariamente sea cierto, debido a las diferencias territoriales importantes que hay en el país y que fueron identificadas anteriormente al desagregar los indicadores a nivel urbano-rural ${ }^{10}$. Las metas restantes no serían alcanzables dada la tendencia de la segunda mitad de la década. La síntesis se describe en la Tabla 5.

De acuerdo con los resultados, las recomendaciones de política serían, entre otras, las siguientes:

- Inclusión en los planes nacionales de desarrollo de políticas, programas y proyectos tendientes a generar empleos suficientes y de calidad a la fuerza laboral del país y a promover condiciones decentes en las vacantes.

10 Para mayor información de trabajo decente por territorios del país, remítase a López (2020) y a DNP (2020). 
Sociedad y Economía N 43 (Mayo - Ago 2021) / e-ISSN: 2389-9050 / e10710914 ¿Qué tan lejos está el ODS \# 8 para Colombia? Una década de medición del trabajo decente

Tabla 5. Logros, metas y retos de ODS \# 8 para Colombia

\begin{tabular}{|c|c|c|c|c|c|c|}
\hline Objetivo & Logro 2019 & $\begin{array}{l}\text { Tasa de } \\
\text { (de)crecimiento } \\
\text { promedio } \\
\text { últimos años }\end{array}$ & Meta 2030 & Proyección 2030 & PP** requeridos & Evaluación \\
\hline $\begin{array}{l}\text { Promover la disminución } \\
\text { sostenida del desempleo a nivel } \\
\text { nacional }\end{array}$ & $\begin{array}{c}\text { Tasa de } \\
\text { desempleo: } \\
10,5 \%\end{array}$ & $+4,2 \%$ & $\begin{array}{c}\text { Tasa de } \\
\text { desempleo: } 6,8 \%\end{array}$ & $\begin{array}{l}\text { Tendencia } \\
\text { creciente }\end{array}$ & $-3,7$ & No se lograría \\
\hline $\begin{array}{l}\text { Crear conciencia nacional frente } \\
\text { a problemática que representa } \\
\text { trabajo infantil en diferentes } \\
\text { grados de vulnerabilidad } \\
\text { (peores formas) }\end{array}$ & $\begin{array}{l}\text { Tasa de trabajo } \\
\text { infantil: } \\
5,9 \% \%^{*}\end{array}$ & $-9,2 \%$ & $\begin{array}{l}\text { Tasa de trabajo } \\
\text { infantil: } \\
6 \%\end{array}$ & $\begin{array}{l}\text { Tendencia } \\
\text { creciente }\end{array}$ & 0 & Ya alcanzable \\
\hline Promover la formalidad laboral & $\begin{array}{l}\text { Tasa de } \\
\text { formalidad: } \\
36,8 \%\end{array}$ & $+1,7 \%$ & $\begin{array}{c}\text { Tasa de } \\
\text { formalidad: } 60 \%\end{array}$ & $45 \%$ & $+26,2$ & Nada alcanzable \\
\hline $\begin{array}{l}\text { Reducir la proporción de jóvenes } \\
\text { que no están empleados y no } \\
\text { aursan estudios ni reciben } \\
\text { capacitación }\end{array}$ & $\begin{array}{l}\text { Tasa de ninis: } \\
22,6 \%\end{array}$ & $+3,1 \%$ & $\begin{array}{l}\text { Tasa de ninis: } \\
\quad 15 \%\end{array}$ & $\begin{array}{l}\text { Tendencia } \\
\text { creciente }\end{array}$ & $-7,6$ & No se lograría \\
\hline $\begin{array}{c}\text { Aumentar la población afiliada } \\
\text { a ARL }\end{array}$ & $\begin{array}{l}\text { Tasa de afiliación: } \\
37,5 \%\end{array}$ & $+3,1 \%$ & $\begin{array}{l}\text { Tasa de afiliación: } \\
48 \%\end{array}$ & $47,6 \%$ & $+10,5$ & Muy alcanzable \\
\hline
\end{tabular}

- Dar direccionamientos para que en los planes regionales y municipales de desarrollo, los gobernadores y alcaldes incluyan estrategias en pro del trabajo decente.

- Expandir el servicio público de empleo en todo el territorio nacional.

- Fortalecer el sistema de inspección, vigilancia y control del Ministerio de Trabajo para que proteja los derechos de los trabajadores y desempleados en el marco de los derechos internacionales del trabajo y el Código Sustantivo del Trabajo.

- Fortalecer los sistemas de información en el país para que puedan ser usados y den información pertinente y oportuna para la toma de decisiones.

- Políticas que mejoren el ambiente económico en el que se desenvuelven las empresas.

- Apoyar técnica y financieramente a las pymes, fami-empresas y medianas empresas para la creación de puestos de trabajo, especialmente aquellas cuyo valor agregado es alto.

- Programas de co(financiamiento) de estudios superiores dirigidos a los jóvenes, especialmente a los más vulnerables.

- Promover la creación de empresas generadoras de empleo formal.

- Dar alivios tributarios y créditos blandos para las empresas formales y nacientes.

- Aumentar la cobertura del sistema de salud, pensión y riesgos laborales.

A nivel local, las estrategias deberían basarse en elaborar planes de empleo e incluir componentes de trabajo decente en los planes de desarrollo territoriales. Y para los empresarios, la tarea es promover trabajos decentes por la vía de modernizar en el marco del desarrollo humano, las relaciones con el trabajador, promoviendo, entre otros, aquellos programas innovadores de bienestar laboral, y flexibilizando el modo de trabajar por medio de teletrabajo y trabajo en casa. 


\section{Anexo}

Tabla A1. Ficha técnica de indicadores propuestos para la medición de trabajo decente en Colombia

Nombre del

Definición del indicador

Fórmula de cálculo

Unidad indicador Dimensión 1: Oportunidades de empleo

$\begin{array}{lll}\text { EMPL-1: Tasa de } & \text { Porcentaje de personas ocupadas (PO) -Trabajó por lo menos } & \text { (PO/PET)*100 }\end{array}$
ocupación una hora remunerada en la semana de referencia; no trabajaron la semana de referencia, pero tenían un trabajo y trabajadores familiares sin remuneración que trabajaron en la semana de referencia por lo menos 1 hora; con respecto a la población de 10 o más años de edad en zona rural, más la población de 12 o más años en zona urbana (población en edad de trabajar, PET)

\begin{tabular}{|c|c|c|c|}
\hline $\begin{array}{l}\text { EMPL-2: Tasa de } \\
\text { desempleo }\end{array}$ & $\begin{array}{l}\text { Porcentaje de personas consideradas como desempleadas (o } \\
\text { que se encuentran buscando empleo) con respecto a la } \\
\text { población que integra la fuerza laboral (población } \\
\text { económicamente activa PEA) }\end{array}$ & $(\mathrm{PD} / \mathrm{PEA}) * 100$ & $\%$ \\
\hline $\begin{array}{l}\text { EMPL-3: Tasa de } \\
\text { ninis }\end{array}$ & $\begin{array}{l}\text { Porcentaje de jóvenes de } 14 \text { a } 28 \text { años que no se encuentran } \\
\text { estudiando ni trabajando (ninis) con respecto a la población } \\
\text { total joven de } 14 \text { a } 28 \text { años de edad }\end{array}$ & (NINIS 14-28 años/ Jóvenes 14-28)*100 & $\%$ \\
\hline $\begin{array}{l}\text { EMPL-4: Tasa de } \\
\text { empleo informal } \\
\text { por tamaño de } \\
\text { empresa }\end{array}$ & $\begin{array}{l}\text { Porcentaje de la población ocupada informal (POIF) con } \\
\text { respecto a la población total ocupada (PO), según definición } \\
\text { del DANE bajo la Resolución de } 1993 \text { de la OIT (DANE, 2009) }\end{array}$ & $(\mathrm{POIF} / \mathrm{PO}) * 100$ & $\%$ \\
\hline $\begin{array}{l}\text { EMPL-4: Tasa de } \\
\text { empleo informal } \\
\text { por afiliación a } \\
\text { SGSSS }\end{array}$ & $\begin{array}{l}\text { Porcentaje de la población ocupada que no está afiliada al } \\
\text { sistema de salud o a pensiones (POIF2) del total de la } \\
\text { población ocupada (PO) }\end{array}$ & (POIF2/PO)*100 & $\%$ \\
\hline $\begin{array}{l}\text { EMPL-5: Tasa } \\
\text { bruta de } \\
\text { participación }\end{array}$ & $\begin{array}{l}\text { Relación porcentual entre la población económicamente activa } \\
\text { (PEA), es decir, aquellas que componen el mercado laboral y la } \\
\text { población total (PT) }\end{array}$ & $(\mathrm{PEA} / \mathrm{PT}) * 100$ & $\%$ \\
\hline $\begin{array}{l}\text { EMPL-5: Tasa } \\
\text { global de } \\
\text { participación }\end{array}$ & $\begin{array}{l}\text { Porcentaje de la fuerza laboral (PEA) con respecto a la } \\
\text { población en edad de trabajar (PET) }\end{array}$ & $($ PEA / PET)*100 & $\%$ \\
\hline $\begin{array}{l}\text { EMPL-6: Tasa de } \\
\text { desempleo por } \\
\text { rangos de edad }\end{array}$ & $\begin{array}{l}\text { Porcentaje de población desempleada (PD) por rangos de } \\
\text { edad (PEAJ) }\end{array}$ & (PDJ / PEAJ)*100 & $\%$ \\
\hline $\begin{array}{l}\text { EMPL-7: Tasa de } \\
\text { desempleo por } \\
\text { nivel educativo }\end{array}$ & $\begin{array}{l}\text { Porcentaje de población que se encuentra en estado de } \\
\text { desempleo (PD) por nivel educativo (ninguno, preescolar, básica } \\
\text { primaria, básica secundaria, media y superior) con respecto al } \\
\text { total de la población económicamente activa (PEA) }\end{array}$ & (PD/ PEA)*100 por nivel & $\%$ \\
\hline $\begin{array}{l}\text { EMPL-8: Posición } \\
\text { ocupacional }\end{array}$ & $\begin{array}{l}\text { Participación porcentual de los ocupados según su situación } \\
\text { ocupacional en el empleo principal }\end{array}$ & (PO por posición ocupacional / PO)*100 & $\%$ \\
\hline $\begin{array}{l}\text { EMPL-9: Tasa de } \\
\text { cuentapropistas y } \\
\text { trabajadores } \\
\text { familiares }\end{array}$ & $\begin{array}{l}\text { Proporción de ocupados cuya situación en el empleo puede } \\
\text { exponerlos a un mayor riesgo económico que las demás } \\
\text { personas ocupadas por ser cuentapropista o trabajadores } \\
\text { familiares }\end{array}$ & $\begin{array}{c}\text { (POCP/PO)*100 } \\
\text { (Número total de trabajadores por cuenta propia y } \\
\text { trabajadores familiares / población ocupada } \\
\text { total)*100 }\end{array}$ & $\%$ \\
\hline $\begin{array}{l}\text { EMPL-10: } \\
\text { Porcentaje de } \\
\text { asalariados no }\end{array}$ & $\begin{array}{l}\text { Participación del empleo asalariado en la ocupación no } \\
\text { agrícola }\end{array}$ & $\begin{array}{c}\text { (PONA / PO)*100 } \\
\text { (Número de ocupados asalariados en el sector no } \\
\text { agrícola / ocupados totales)*100 }\end{array}$ & $\%$ \\
\hline \multicolumn{4}{|c|}{ Dimensión 2: Ingresos suficientes y productividad } \\
\hline $\begin{array}{l}\text { EARN-1: Tasa de } \\
\text { ocupados pobres }\end{array}$ & $\begin{array}{l}\text { Porcentaje de la población que, si bien se encuentra ocupada (PO), } \\
\text { vive en la pobreza (POP); esto es, el ingreso total familiar per } \\
\text { cápita es inferior a la línea de pobreza según año y territorio (línea } \\
\text { de pobreza nacional, } 13 \text { áreas y urbano y rural) }\end{array}$ & $(\mathrm{POP} / \mathrm{PO}) * 100$ & $\%$ \\
\hline $\begin{array}{l}\text { EARN-2: Tasa de } \\
\text { asalariados con } \\
\text { bajos ingresos }\end{array}$ & $\begin{array}{l}\text { Relación porcentual de ocupados asalariados }(\mathrm{OA}) \text { que } \\
\text { trabajan por salarios bajos (el ingreso laboral es menor a } 2 / 3 \\
\text { del valor de la mediana del salario según año y territorio, } O A B \text { ) }\end{array}$ & $(\mathrm{OAB} / \mathrm{OA}) * 100$ & $\%$ \\
\hline
\end{tabular}


Tabla A1. Ficha técnica de indicadores propuestos para la medición de trabajo decente en Colombia (continuación)

Nombre del

Definición del indicador

Fórmula de cálculo

Unidad

indicador

Dimensión 2: Ingresos suficientes y productividad

EARN-3: Ingresos Ingreso laboral del primer y segundo empleo, monetario y en $\quad$ ((Ingreso laboral mensual / Horas trabajadas a la $\quad \mathrm{N}^{\circ}$

laborales medios

especie (con imputaciones), medio por hora trabajada al mes semana*4) / PO)

por hora

\begin{tabular}{|c|c|c|c|}
\hline $\begin{array}{l}\text { EARN-4: Salario } \\
\text { promedio real }\end{array}$ & $\begin{array}{l}\text { Ingreso laboral mensual promedio de asalariados a precios } \\
\text { constantes de } 2018 \text { (IPC 2018=100) }\end{array}$ & $\begin{array}{l}\text { (Ingreso laboral mensual de asalariados / } \\
\text { Promedio IPC mensual según año)*100 }\end{array}$ & $\mathrm{N}^{\circ}$ \\
\hline $\begin{array}{l}\text { EARN-5: Salario } \\
\text { mediano como } \\
\text { porcentaje del } \\
\text { salario mediano }\end{array}$ & $\begin{array}{l}\text { Porcentaje del salario mediano mensual según territorio y año, } \\
\text { con respecto al salario mínimo mensual legal vigente }\end{array}$ & $\begin{array}{l}\text { (Mediana del ingreso laboral mensual de } \\
\text { asalariados / SMMLV según año)*100 }\end{array}$ & $\%$ \\
\hline $\begin{array}{l}\text { Tasa dependencia } \\
\text { económica de los } \\
\text { hogares }\end{array}$ & $\begin{array}{l}\text { Porcentaje de hogares con dependencia económica, esto es, } \\
\text { que la razón entre el total de integrantes del hogar y el total de } \\
\text { integrantes ocupados (con un ingreso laboral superior a 0) es } \\
\text { mayor a } 3 \text {, con respecto al total de hogares. }\end{array}$ & $\begin{array}{l}\text { (Hogares dependientes económicamente/Total de } \\
\text { hogares)*100 }\end{array}$ & $\%$ \\
\hline \multicolumn{4}{|c|}{ Dimensión 3: Tiempo de trabajo decente } \\
\hline $\begin{array}{l}\text { TIME-1: Tiempo de } \\
\text { trabajo excesivo }\end{array}$ & $\begin{array}{l}\text { Porcentaje de ocupados (PO) que laboran en la semana más } \\
\text { de las } 48 \text { horas legales (POE), en el primer empleo }\end{array}$ & (POE/PO)*100 & $\%$ \\
\hline $\begin{array}{l}\text { TIME-2: Porcentaje } \\
\text { de ocupados según } \\
\text { jornada laboral }\end{array}$ & $\begin{array}{l}\text { Participación porcentual de los ocupados (PO) según rango de } \\
\text { horas trabajadas a la semana, en el primer empleo }\end{array}$ & (PO según horas de trabajo / PO)*100 & $\%$ \\
\hline $\begin{array}{l}\text { TIME-3: Jornada } \\
\text { laboral promedio }\end{array}$ & $\begin{array}{l}\text { Número de horas trabajadas a la semana en promedio, en el } \\
\text { primer empleo }\end{array}$ & Sumatoria horas trabajadas / PO & $\%$ \\
\hline $\begin{array}{l}\text { TIME-4: Tasa de } \\
\text { subempleo } \\
\text { objetivo }\end{array}$ & $\begin{array}{l}\text { Relación porcentual entre el número de personas en subempleo } \\
\text { objetivo (SO), según DANE (comprende a quienes tienen el } \\
\text { deseo, y han hecho una gestión para materializar su aspiración } \\
\text { y están en disposición de efectuar el cambio, y personas que } \\
\text { integran la fuerza laboral) y el total de ocupados (PO) }\end{array}$ & $(\mathrm{SO} / \mathrm{PEA}) * 100$ & $\%$ \\
\hline \multicolumn{4}{|c|}{ Dimensión 4: Conciliación del trabajo, la vida familiar y la vida personal } \\
\hline $\begin{array}{l}\text { Tasa de tiempo no } \\
\text { remunerado con } \\
\text { respecto al total }\end{array}$ & $\begin{array}{l}\text { Participación porcentual de las horas remuneradas de } \\
\text { población ocupada con respecto al total de horas destinadas } \\
\text { en actividades remuneradas y no remuneradas para la } \\
\text { población ocupada }\end{array}$ & $\begin{array}{l}\text { (\# de horas de trabajo no remunerado semanales } \\
\text { / \# de horas en actividades remuneradas y no } \\
\text { remuneradas de } \mathrm{PO})^{*} 100\end{array}$ & $\%$ \\
\hline \multicolumn{4}{|c|}{ Dimensión 5: Trabajo que debería abolirse } \\
\hline $\begin{array}{l}\text { ABOL-1: Tasa de } \\
\text { trabajo infantil }\end{array}$ & $\begin{array}{l}\text { Porcentaje de la población infantil (5-17 años) que se encuentra } \\
\text { ocupada (POI) frente a la población total de 5-17 años (PIN). } \\
\text { Se usa el módulo de trabajo infantil de la GEIH }\end{array}$ & $(\mathrm{POI} / \mathrm{PIN}) * 100$ & $\%$ \\
\hline $\begin{array}{l}\text { Tasa de trabajo } \\
\text { infantil de } 10 \text { a } 17 \\
\text { años }\end{array}$ & $\begin{array}{l}\text { Porcentaje de la población infantil (10-17 años) que se } \\
\text { encuentra ocupada y labora más de } 15 \text { horas a la semana } \\
\text { (POI2), frente a la población total de 10-17 años (PIN2) }\end{array}$ & $(\mathrm{POI} 2 / \mathrm{PIN} 2) * 100$ & $\%$ \\
\hline \multicolumn{4}{|c|}{ Dimensión 6: Estabilidad y seguridad del trabajo } \\
\hline $\begin{array}{l}\text { STAB-1: Tasa de } \\
\text { empleo precario }\end{array}$ & $\begin{array}{l}\text { Porcentaje de ocupados sin contrato, con contrato a término fijo } \\
\text { o verbal o vinculados a través de empresas de servicios } \\
\text { temporales, cooperativas de trabajo asociado o empresa } \\
\text { asociativa de trabajo con respecto al total de ocupados (PO) }\end{array}$ & $\begin{array}{l}\text { (Población ocupada sin contrato, con contrato } \\
\text { verbal o a término fijo o vinculados temporalmente, } \\
\text { con asociativas o cooperativas de trabajo / } \\
\text { PO)*100 }\end{array}$ & $\%$ \\
\hline $\begin{array}{l}\text { STAB-2: } \\
\text { Antigüedad en el } \\
\text { trabajo }\end{array}$ & $\begin{array}{l}\text { Antigüedad laboral de los trabajadores en su trabajo actual o } \\
\text { principal o con su empleador actual. } \\
\text { Promedio de la duración del empleo }\end{array}$ & $\begin{array}{l}\text { (Sumatoria de horas / PO)*100 } \\
\text { Número de meses en total trabajados / Población } \\
\text { ocupada }\end{array}$ & $\mathrm{N}^{\circ}$ \\
\hline \multicolumn{4}{|c|}{ Dimensión 7: Igualdad de oportunidades y trato en el trabajo } \\
\hline $\begin{array}{l}\text { EQUA-1: Índice de } \\
\text { Duncan } \\
\text { (Segregación } \\
\text { ocupacional por } \\
\text { sexo) }\end{array}$ & $\begin{array}{l}\text { Indicador de discriminación en la medida en que es expresión } \\
\text { de la tradicional división sexual del trabajo, que subvalora } \\
\text { aquellas actividades de tradición doméstica o que provienen y } \\
\text { han sido desarrolladas por el trabajo no remunerado de la } \\
\text { mujer }\end{array}$ & $\begin{array}{c}0,5 * \text { Sumatoria }|\mathrm{Mi} / \mathrm{M}-\mathrm{Hi} / \mathrm{H}| \text { desde } \mathrm{i}=1 \text { a } 82 \\
\text { donde l es el número de ocupaciones definidas por } \\
\text { ClUO-88 }\end{array}$ & Razón \\
\hline $\begin{array}{l}\text { EQUA-3: Brecha } \\
\text { salarial por } \\
\text { género }\end{array}$ & $\begin{array}{l}\text { Diferencia entre el salario promedio (S) por hora laborada, del } \\
\text { primer y segundo empleo, por pago monetario y en especie, de } \\
\text { los hombres y el de las mujeres }\end{array}$ & $\begin{array}{l}\text { (Salario promedio } \\
\text { por hora de los hombres - Salario promedio por } \\
\text { hora de las mujeres) }\end{array}$ & $\mathrm{N}^{\circ}$ \\
\hline
\end{tabular}


Tabla A1. Ficha técnica de indicadores propuestos para la medición de trabajo decente en Colombia (continuación)

Nombre del

indicador

\begin{tabular}{|c|c|c|c|}
\hline indicador & & & de medidc \\
\hline \multicolumn{4}{|c|}{ Dimensión 7: Igualdad de oportunidades y trato en el trabajo } \\
\hline $\begin{array}{l}\text { Brecha de horas } \\
\text { trabajadas por } \\
\text { género }\end{array}$ & $\begin{array}{l}\text { Diferencia de las horas trabajadas en el empleo principal y } \\
\text { secundario, en promedio a la semana, de los hombres }(\mathrm{Hh}) \\
\text { respecto a las horas trabajadas en el empleo principal o } \\
\text { secundario, en promedio a la semana, de las mujeres }(\mathrm{Hm})\end{array}$ & $\begin{array}{c}\text { [(Horas laborales semana hombres/Total de } \\
\text { Hombres ocupados - (Horas laborales semana } \\
\text { mujeres/Total de mujeres ocupadas)] }\end{array}$ & $\mathrm{N}^{\circ}$ \\
\hline $\begin{array}{l}\text { EQUA-2: } \\
\text { Porcentaje de } \\
\text { mujeres en cargos } \\
\text { directivos }\end{array}$ & $\begin{array}{l}\text { Relación porcentual entre el número de mujeres ocupadas en } \\
\text { cargo directivo o de funcionarios superiores (MOD) del total de } \\
\text { personas en este tipo de cargos (OD) }\end{array}$ & $(\mathrm{MOD} / \mathrm{OC}) * 100$ & $\%$ \\
\hline \multicolumn{4}{|c|}{ Dimensión 8: Entorno de trabajo seguro } \\
\hline $\begin{array}{l}\text { SAFE-2: Tasa de } \\
\text { accidentes } \\
\text { laborales }\end{array}$ & $\begin{array}{l}\text { Relación porcentual de accidentes de trabajo (registrados) con } \\
\text { respecto al total de ocupados registrados }\end{array}$ & $\begin{array}{l}\text { (Número de accidentes laborales registrados/ } \\
\text { Población empleada registrada)*100 }\end{array}$ & $\%$ \\
\hline $\begin{array}{l}\text { SAFE-2: Tasa de } \\
\text { enfermedades en } \\
\text { el trabajo }\end{array}$ & $\begin{array}{l}\text { Relación porcentual de enfermedades laborales (registrados) } \\
\text { con respecto al total de ocupados registrados }\end{array}$ & $\begin{array}{l}\text { (Número de enfermedades laborales registrados/ } \\
\text { Población empleada registrada)*100 }\end{array}$ & $\%$ \\
\hline $\begin{array}{l}\text { Tasa de afiliación } \\
\text { a riesgos } \\
\text { laborales }\end{array}$ & $\begin{array}{l}\text { Relación porcentual entre la población ocupada afiliada al } \\
\text { sistema general de riesgos laborales (PR) y el número total de } \\
\text { ocupados (PO) }\end{array}$ & $(\mathrm{PR} / \mathrm{PO}) * 100$ & $\%$ \\
\hline \multicolumn{4}{|c|}{ Dimensión 9: Seguridad social } \\
\hline $\begin{array}{l}\text { SECU-1: } \\
\text { Participación de } \\
\text { los beneficiarios } \\
\text { de pensión de } \\
\text { vejez }\end{array}$ & $\begin{array}{l}\text { Porcentaje de la población adulta mayor que recibe pensión de } \\
\text { vejez con respecto al total de población adulta mayor. En } \\
\text { mujeres, para aquellas que tienen } 57 \text { años o más, y en hombres, } \\
\text { para aquellos que tienen } 62 \text { años o más }\end{array}$ & $\begin{array}{c}\text { (PAP / PA)*100 } \\
\text { (Población receptora de pensión / Total Población } \\
\text { según edad)*100 }\end{array}$ & $\%$ \\
\hline $\begin{array}{l}\text { SECU-4: Tasa de } \\
\text { cotizantes en } \\
\text { fondos de } \\
\text { pensiones }\end{array}$ & $\begin{array}{l}\text { Porcentaje de la fuerza laboral, ocupados como desempleados } \\
\text { (PEA), que cotiza en un fondo obligatorio o voluntario de } \\
\text { pensiones (POCP) }\end{array}$ & $\begin{array}{c}\text { (POCP/PEA)*100 } \\
\text { (Población de la fuerza laboral que cotiza a un } \\
\text { fondo de pensiones / Población económicamente } \\
\text { activa)*100 }\end{array}$ & $\%$ \\
\hline \multicolumn{4}{|c|}{ Dimensión 10: Diálogo social, representación de los ocupados y empleadores } \\
\hline $\begin{array}{l}\text { DIAL-1: Tasa de } \\
\text { sindicalización }\end{array}$ & Porcentaje de la población ocupada afiliada a sindicatos & $\begin{array}{l}\text { Población ocupada que hace parte de una } \\
\text { asociación gremial-sindical / PO }\end{array}$ & $\%$ \\
\hline $\begin{array}{l}\text { DIAL-3: Tasa de } \\
\text { cobertura de la } \\
\text { negociación } \\
\text { colectiva }\end{array}$ & $\begin{array}{l}\text { Número de convenios firmados como negociación colectiva } \\
\text { según tipo (convención colectiva, pactos y contratos sindicales) }\end{array}$ & Número de convenios firmados según tipo & $\mathrm{N}^{\circ}$ \\
\hline
\end{tabular}

Nota: * Los códigos son los definidos por la OIT. Los indicadores sin código corresponden a aquellos que son propuestos para medir el trabajo decente en Colombia.

Fuente: elaboración propia.

\section{Referencias}

Alcaldía Mayor de Bogotá. (2015). Decreto 380 de 2015. http://www.desarrolloeconomico.gov.co/sites/ default/files/planeacion/7._Decreto_380_de_2015.pdf

Asamblea Nacional Constituyente. (1991). Constitución Política de Colombia. https://www.corteconstitucional. gov.co/inicio/Constitucion\%20politica\%20de\%20Colombia.pdf

Anker, R., Chernyshev, I., Egger, P., Mehran, F. y Ritter, J. (2003). La medición del trabajo decente con indicadores estadísticos. Revista Internacional del Trabajo, 122(2), 161-195. https://doi.org/10.1111/ j.1564-913X.2003.tb00172.x

Cárdenas, J. (2013). El impacto de la participación femenina en el mercado laborales de los hombres en Colombia desde 1984 hasta 2012 (tesis de maestría). Universidad del Rosario, Bogotá, Colombia. 
Sociedad y Economía N 43 (Mayo - Ago 2021) / e-ISSN: 2389-9050 / e10710914

¿Qué tan lejos está el ODS \# 8 para Colombia? Una década de medición del trabajo decente

Comité Interinstitucional Nacional. (2008). Estrategia nacional para prevenir y erradicar las peores formas de trabajo infantil y proteger al joven trabajador. 2008-2015. https://app2.mintrabajo.gov.co/siriti/ info/estrategia_colombia_2008_2015.pdf

Concejo de Medellín. (2013). Acuerdo 64 de 2013. Por medio del cual se establece la Política Pública de Trabajo Decente en la Ciudad de Medellín. https://www.medellin.gov.co/normograma/docs/astrea/ docs/a_conmed_0064_2013.htm

DANE -Departamento Administrativo Nacional de Estadística-. (2009). Boletín especial de prensa. Medición del empleo informal. https://www.dane.gov.co/files/investigaciones/boletines/ech/ech_informalidad/ bolet_ech_informalidad_sep_nov2009.pdf

DANE -Departamento Administrativo Nacional de Estadística-. (2018). Mercado laboral. Principales resultados. https://www.dane.gov.co/files/investigaciones/boletines/ech/ech/pres_web_empleo_ resultados_mar_18.pdf

DANE -Departamento Administrativo Nacional de Estadística-. (2019). Boletín técnico. Pobreza Monetaria en Colombia 2018. https://www.dane.gov.co/files/investigaciones/condiciones_vida/pobreza/2018/ bt_pobreza_multidimensional_18.pdf

DANE -Departamento Administrativo Nacional de Estadística-. (2020). Gran Encuesta Integrada de Hogares. http://microdatos.dane.gov.co/index.php/catalog/MICRODATOS/about_collection/23/1

DNP -Departamento Nacional de Planeación-. (2015). Plan Nacional de Desarrollo 2014-2018. Todos por un nuevo país. https://colaboracion.dnp.gov.co/CDT/PND/PND\%202014-2018\%20Tomo\%201\%20internet. pdf

DNP -Departamento Nacional de Planeación-. (2019). Plan Nacional de Desarrollo 2018-2022. Pacto por Colombia, pacto por la equidad. https://colaboracion.dnp.gov.co/CDT/Prensa/PND-Pacto-por-Colombiapacto-por-la-equidad-2018-2022.pdf

DNP -Departamento Nacional de Planeación-. (2020). Trabajo decente y crecimiento económico. https:// www.ods.gov.co/es/objetivos/trabajo-decente-y-crecimiento-economico

Duncan, O. y Duncan, B. (1995). A methodological analysis of segregation indexes. American Sociological Review, 20(2), 210-217. https://doi.org/10.2307/2088328

ENS -Escuela Nacional Sindical-. (2020). Informes SISLAB. http://www.ens.org.co/lee-y-aprende/lee-ydescarga-nuestras-publicaciones/informes-sislab/

Fasecolda -Federación de Aseguradores Colombianos-. (2020). RLDatos Riesgos Laborales. https://sistemas. fasecolda.com/rldatos/reportes/xclasegrupoactividad.aspx

Fundación Ideas para la Paz. (2014). Guía de trabajo decente, Guías Colombia en empresas, derechos humanos y DIH. http://cdn.ideaspaz.org/media/website/document/5aled81d548ce.pdf

Gálvez, E., Gutiérrez, E. y Picazzo, E. (2011). El trabajo decente: nuevo paradigma para el fortalecimiento de los derechos sociales. Revista Mexicana de Sociología, 73(1), 73-104. http://dx.doi.org/10.22201/ iis.01882503p.2011.1.23564

ILO -International Labour Organization-. (2008). Measurement of decent work (Discussion paper for the Tripartite Meeting of Experts on the Measurement of Decent Work). ILO

ILO -International Labour Organization-. (2013). Decent work indicators: guidelines for producers and users of statistical and legal framework indicators. https://www.ilo.org/wcmsp5/groups/public/---dgreports/--integration/documents/publication/wcms_229374.pdf

López, S. (2020). Caracterización del empleo en Colombia: Un análisis del trabajo decente para Medellín y otras ciudades principales del país 2010-2018. Apuntes del Cenes, 39(69), 169-217. https://doi. org/10.19053/01203053.v39.n69.2020.9915 
Ministerio de Hacienda y Crédito Público. (2019). Marco Fiscal de Mediano Plazo 2019. https://www. minhacienda.gov.co/webcenter/ShowProperty?nodeld=\%2FConexionContent\%2FWCC_CLUSTER$111638 \% 2$ F\%2FidcPrimaryFile\&revision=latestreleased

MinTrabajo -Ministerio del Trabajo-. (2015). Recomendaciones para promoción del empleo en el marco del trabajo decente a entes territoriales 2016-2019. Política pública de empleo y trabajo decente. https:// www.casanare.gov.co/Dependencias/Salud/Documentos\%20de\%20Inters/Recomendaciones\%20para\%20 la\%20promocion\%20del\%20empleo\%20en\%20el\%20marco\%20del\%20trabajo\%20decente\%202016-2019. pdf

MinTrabajo -Ministerio del Trabajo-. (2020). Fuente de Información Laboral de Colombia FILCO. http://filco.mintrabajo.gov.co/FILCO/;jsessionid=KIZOzjMJat6LeCz3QXumHep622KQodWPjVn7aKM4pzdSGdgcDUH!1377569356

OCDE -Organización para la Cooperación y el Desarrollo Económicos-. (2019). Estudios Económicos de la OCDE: Colombia 2019. OECD Publishing. https://doi.org/10.1787/805f2a79-es

OIT -Organización Internacional del Trabajo-. (1999). Memoria del Director General: Trabajo decente (ponencia). 87a Reunión Conferencia Internacional del Trabajo, Ginebra, Suiza.

OIT -Organización Internacional del Trabajo-. (2015). Trabajo decente. https://www.ilo.org/global/topics/ decent-work/lang--es/index.htm

Pineda, J. y Acosta C. (2011). Calidad del trabajo: aproximaciones teóricas y estimación de un índice compuesto. Ensayos sobre Política Económica, 29(65), 60-105. https://doi.org/10.32468/Espe.6502

Pineda, J., Farné, S., Jiménez, D. y Rodríguez, V. (2013). Dimensiones e indicadores de trabajo decente para Bogotá. En J. Pineda (Comp.), Trabajo decente en Bogotá. Diagnóstico, Análisis y perspectivas (pp. 15-77). Ediciones Uniandes.

PNUD -Programa de las Naciones Unidas para el Desarrollo-. (2016). Desde los ODM hasta el desarrollo sostenible para todos. Lecciones aprendidas tras 15 años de práctica. http://www.undp.org/content/ dam/undp/library/SDGs/Spanish/ES_f_UNDP_MDGs-to-SDGs_web.pdf

PNUD -Programa de las Naciones Unidas para el Desarrollo-. (2018). ODS en Colombia: Los retos para 2030. https://www.undp.org/content/dam/colombia/docs/ODS/undp_co_PUBL_julio_ODS_en_Colombia_los_ retos_para_2030_ONU.pdf

PNUD Colombia -Programa de las Naciones Unidas para el Desarrollo en Colombia-. (2021). Objetivos de Desarrollo Sostenible. https://www.co.undp.org/content/colombia/es/home/sustainable-developmentgoals.html

Sen, A. (2000). Trabajo y derechos. Revista Internacional del Trabajo, 1 19(2), 129-139.

Somavía, J. (2014). El trabajo decente. Una lucha por la dignidad humana. OIT.

The Economist. (2019). The struggle to reduce the "motherhood penalty". https://www.economist.com/ graphic-detail/2019/05/31/the-struggle-to-reduce-the-motherhood-penalty 